\title{
Efficiency Assesment of Chitosan Graphene Oxide Composite in Aniline Removal from Aqueous Solutions
}

\author{
F. Azadbakht ${ }^{1}$, R. Rezaei Kalantar ${ }^{2}$, A. Esrafili ${ }^{3}$, S Shojaeyan ${ }^{1}$, M Yegane Badi ${ }^{1}$, M Gholami *2 \\ 1. MSc Student in Environmental Health Engineering, School of Public Health, \\ Iran University of Medical Sciences, Tehran, Iran \\ 2. Professor, Department of Environmental Health Engineering, School of Public Health, \\ Iran University of Medical Sciences, Tehran, Iran \\ 3. Assistant Professor, Department of Environmental Health Engineering, School \\ of Environmental Health, Iran University of Medical Sciences, Tehran, Iran \\ *E-mail: gholamim@iums.ac.ir
}

Received: 2 Sep 2018 ; Accepted: 30 Jan 2019

\begin{abstract}
Background and Objectives: Aniline is a toxic compound characterized by high solubility in water ( 3.5 percent; $35000 \mathrm{mg} / \mathrm{L}$ ) leading to increased presence risk of aniline in wastewater. The presence of this compound in the blood causes the formation of met hemoglobin and prevent oxygen uptake and plays a key role in chemical asphyxiation, moreover, it has been thought as a carcinogenic risk factor to humans. Therefore, this study aims to synthesizes chitosan graphene oxide and determine the usefulness of using this absorbent to remove aniline from aqueous solutions.

Methods: Chitosan Graphene Oxide (CGO) which was prepared from graphite powder by adapting the procedure used by Hummer, doped with chitosan and the characterization of CGO were determined by Scanning Electron Microscope (SEM), Fourier Transform Infrared Spectroscopy (FTIR) and X-ray Powder Diffraction (XRD). To optimize the conditions, parameters including adsorbent dosage $(0.2,0.4,0.6,0.8,1,1.25$ and $1.5 \mathrm{~g} / \mathrm{L}), \mathrm{pH}(2,4,6,8,10)$, contact time $(5,15,30,45$, $60,90,120 \mathrm{~min})$ and aniline concentrations $(50,100,150,200$ and $300 \mathrm{mg} / \mathrm{L})$ were evaluated in a total of 126 tests. Finally Chitosan Graphene Oxide was used for aniline removal from aqueous solutions.

Results: The results of present study showed that with increase in contact time and absorbent dosage and with decrease in aniline concentration, removal efficiency tend to increase. $\mathrm{PH}=6$, time $=30 \mathrm{~min}$, absorbent dose $=1 \mathrm{~g} / \mathrm{L}$ and concentration of aniline $=50 \mathrm{mg} / \mathrm{L}$ were obtained as optimum conditions. Under optimum condition $(\mathrm{pH}=6$, time $=30 \mathrm{~min}$, absorbent dose $=1 \mathrm{~g} / \mathrm{L}$ and concentration of aniline $=50 \mathrm{mg} / \mathrm{L}$ ) the highest efficiency of aniline removal is $\% 93.14$. The adsorption isotherm showed that absorption process correlates well with Langmuir adsorption isotherm $\left(\mathrm{R}^{2}>0.9996\right)$. Reaction kinetics complies with Pseudo-second order model with correlation coefficient of $\left(\mathrm{R}^{2}=0.9799\right)$. In the study of thermodynamics, negative values of $\Delta \mathrm{H}^{\circ}$ and $\Delta \mathrm{G}^{\circ}$ respectively illustrate that reactions are exothermic and spontaneous.

Conclusion: chitosan graphene oxide composite has the ability to remove aniline effectively from aqueous solutions. And also it can be used as an efficient adsorbent for related aqueous solutions.
\end{abstract}

Keywords: Adsorption, Aniline, Chitosan graphene oxide 


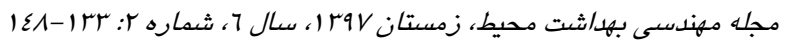

\title{
ارزيابى كارايى كاميوزيت كيتوزان گرافن-اكسايد در حذف آنيلين از محلولهاى آيى
}

\author{
فاطمه آزادبخت'، روشنك رضايى كلانترى'، على اسر افيلى"، سميرا شجاعيان'، مجتبى يحانه بادى'، ميترا غلامى' \\ ' دانشجوى كارشناسى ارشد مهندسى بهداشت محيط، دانشكده بهداشت، دانشكاه علوم يزشكى ايران، تهران، ايران

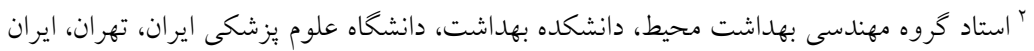

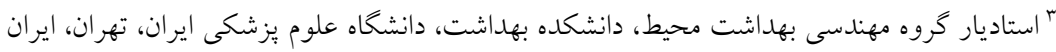

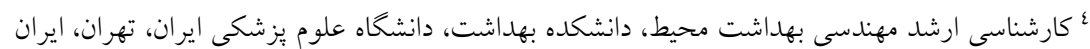

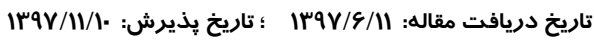

\section{جكيده}

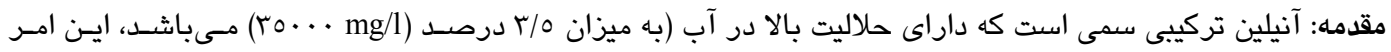

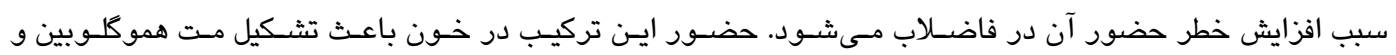

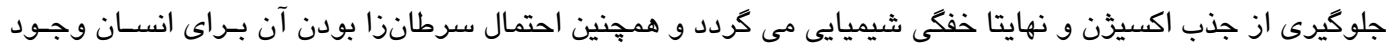

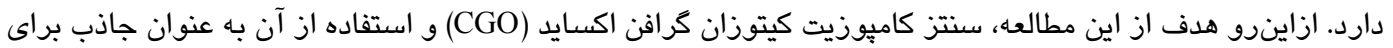

$$
\text { حذف آنيلين از محلولهاى آبى مى باشيد. }
$$

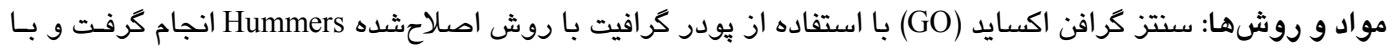

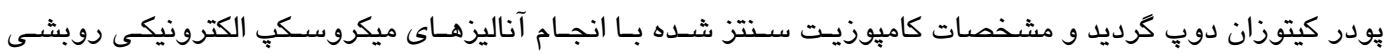
(Fourier transform infrared spectroscopy (Scanning Electron Microscope (SEM))

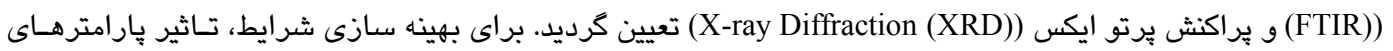

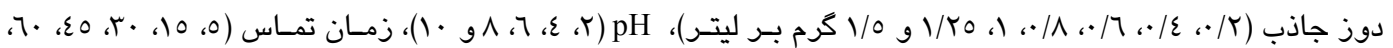

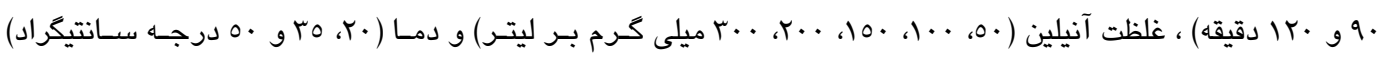

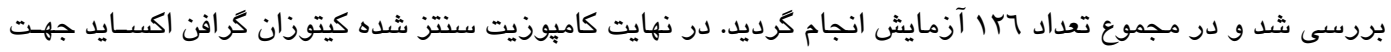

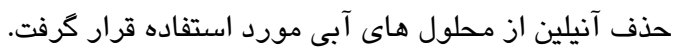

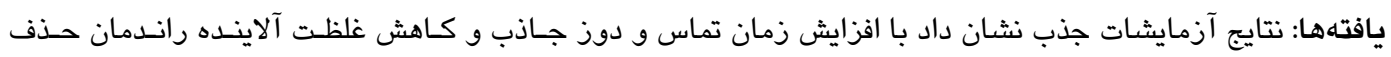

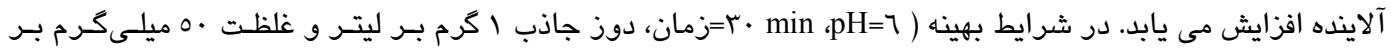

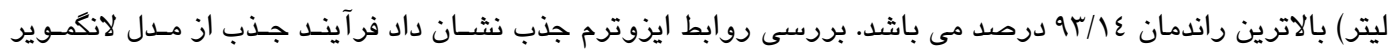

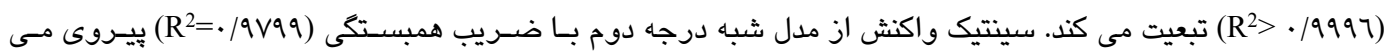

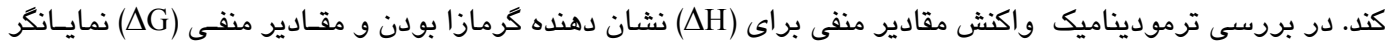

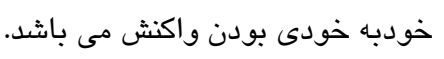

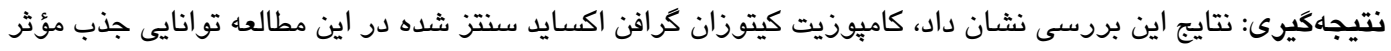

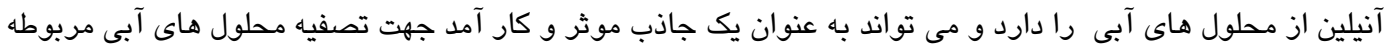
مورد استفاده قرار كيرد. 
روشهاى فوق الذكر بالا مى باشد و محصولات جانبى سـمى

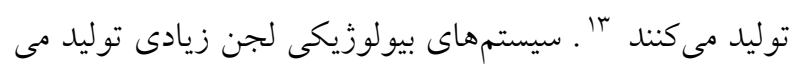

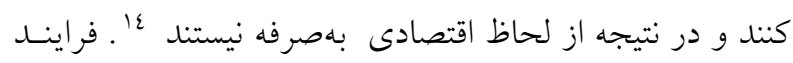
جذب مزاياى متعددى ازجمله هزينه يايين، بهرهبردارى آسـان،

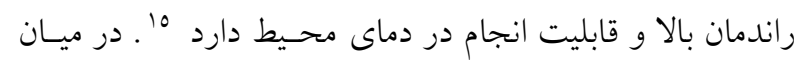

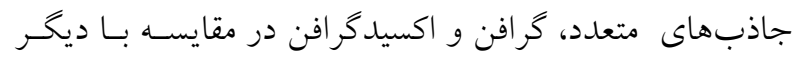
جاذبهاى داراى يايه كربن مانــــ كـربن فعـال و كـربن نـانو

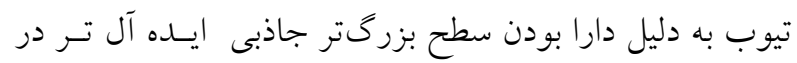

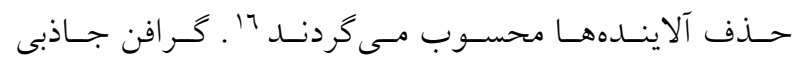

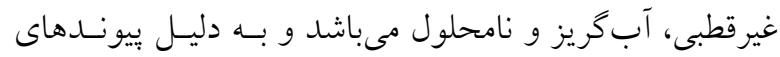
كوو الانسى قوى در حلال به سختى حل مسى شـود، بـه همسين

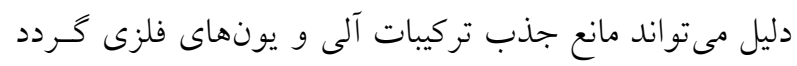

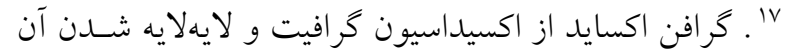

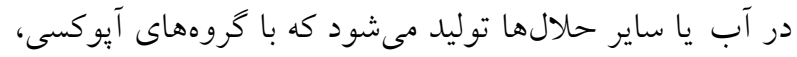

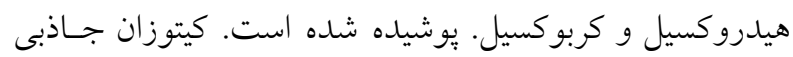

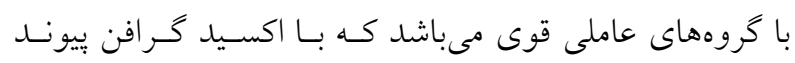

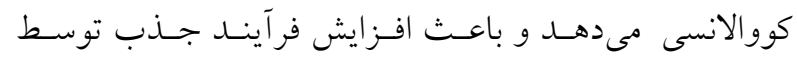

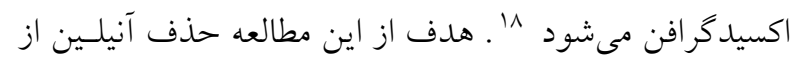

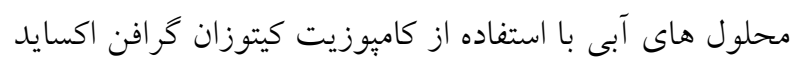

\section{مواد و روشها مواد و تجهيزات}

مواد موردنياز در اين مطالعه شامل كيتـوزان (C) $\left(\mathrm{C}_{8} \mathrm{H}_{13} \mathrm{NOO}_{5}\right.$

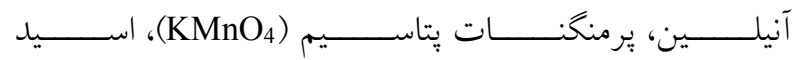

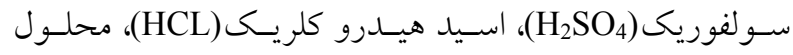
كلوتار آلدهيد (C) $\left(\mathrm{CH}_{3} \mathrm{OH}\right)\left(\mathrm{C}_{2} \mathrm{H}_{5} \mathrm{OH}\right)$
مقدمه آنيلين يا آمينوبنزن يكى تركيب آلى مىباشد كـهـ بـه عنـوان

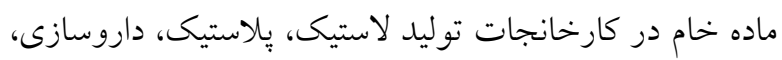

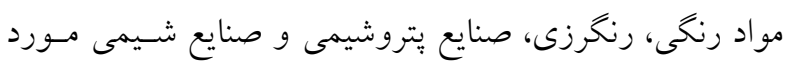

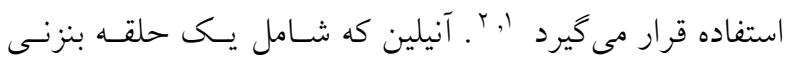

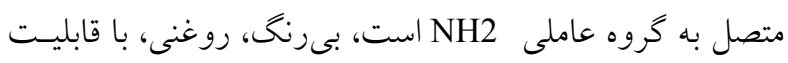

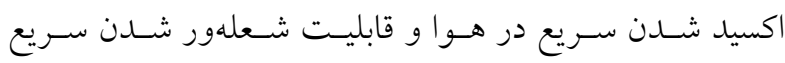

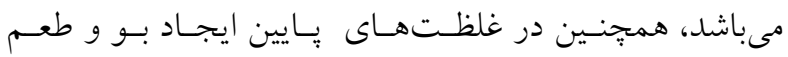

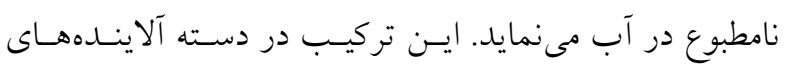

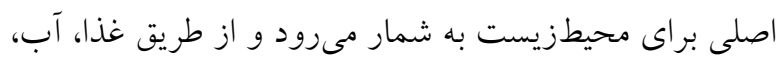
هواى آلوده و يوست وارد بدن انسـان مسى شـود كـه احتمـال

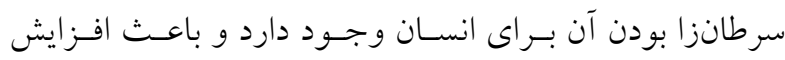

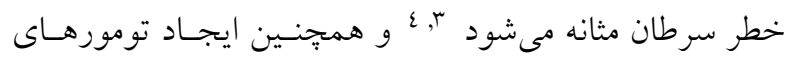
سرطانى در حيوانات مىنمايد ْ. حضور اين تركيب در خـون باعث تشكيل مت همو كلوبين و جلو كيرى از جذب اكسيزن و

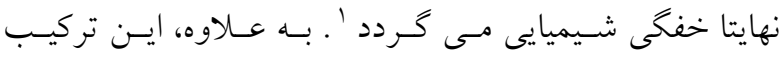
شيميايى مى تواند به كليه ، كبد ، استخوان و مغز آسيب برساند

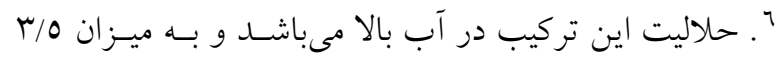

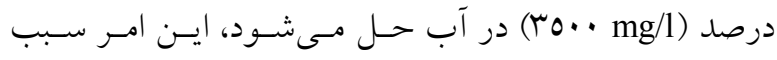

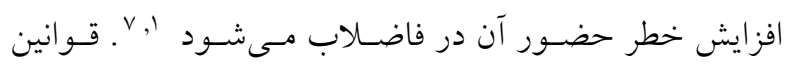

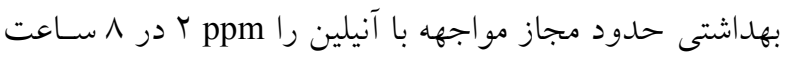

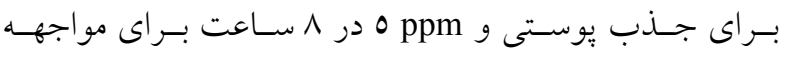
تنفسى تعيين كرده است. سازمان حفاظت محيطزيست آمريكا

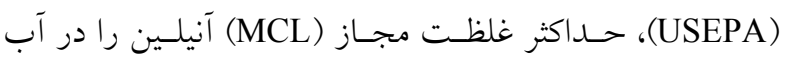

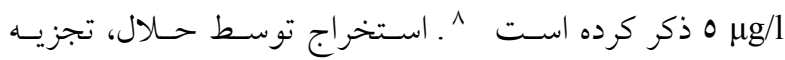

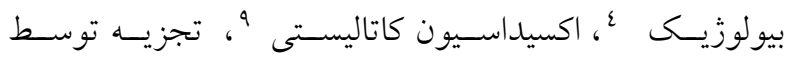

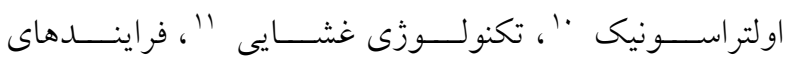

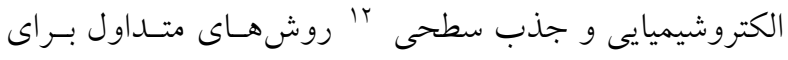

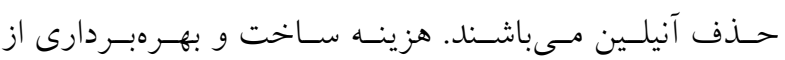


فاطمه آزادبخت و همكاران

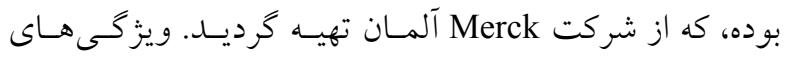
فيزيكى و شيميايى آنيلين در جدول آورده آورده شده است.

جدول ا: ويزكى هاى فيزيكى و شيميايى آنيلين 19

\begin{tabular}{|c|c|c|c|}
\hline فرمول شيميايى & نقطه جوش (C'C) & PKa & جرم مولى (gmol-1) \\
\hline $\mathrm{C}_{6} \mathrm{H}_{5} \mathrm{NH}_{2}$ & $1 \wedge \varepsilon$ & $\varepsilon / 7$ & $9 \pi / 1 \pi$ \\
\hline
\end{tabular}

اكسايد حاصل گرديد ${ }^{17}$ سبس :ِودر گرافن اكسايد به دست آمده در مرحله قبلى، به يك ظرف حساوى ml . مححلـول I. اسيد استيك افزوده گرديد و به مدت •ب دقيقه در دماى اتـاق، تحت امواج اولتراسونيك قرار گرفت. سيس 0 • • گرم كيتـوزان به مواد اضافه شده و به مدت يكى ساعت ديخــ تحست امـواج اولتراسونيك قرار گرفت. يس از كذشـت با ســاعت محلــول

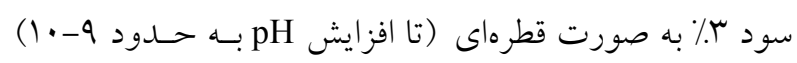

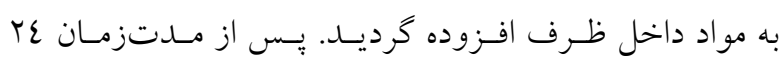
ساعت بيدهاى تشكيل شده با استفاده از آب مقطر تـا رسـيدن

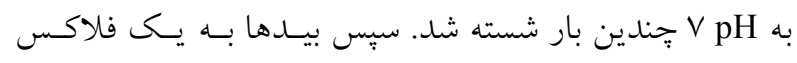

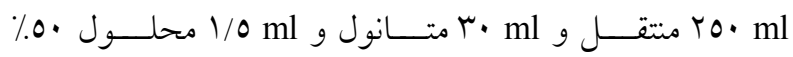
كلوتار آلدهيد به آنها افزوده گرديد و مخلوط حاصل به مدت ه ساعت در دمـاى اتـاق بـر روى يـك شـيكر هــم زده شـــ. درنهايت بيدها فيلتر شده و جهندين بار با اتـانول و سـيس آب

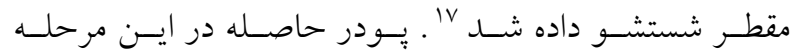
كاميوزيت كيتوزان- كرافن اكسايد بود. مشخصات كامبوزيـت سنتز شده با انجام آناليزهاى ميكروسكب الكترونيكى روبشىى (Scanning Electron Microscope (SEM)) مـادون قرمـز Fourier transform infrared spectroscopy

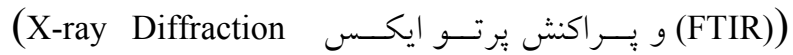
تعيين كرديد. (XRD))

\section{روش اجراى مطالعه}

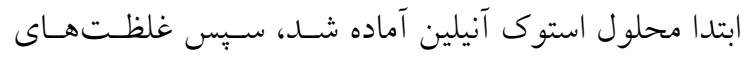
مختلف از استوك تهيه كرديد. در بززوهش حاضـر، بـه منظـور
براى تهيه كليه محلولهاى آزمايش از آب ديونيزه استفاده

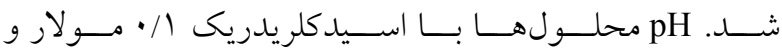
هيدروكسيدسديم l/ • مولار تنظيم كرديد و pH محلولهـا بـا دستخاه pH سنج (HACH-Ha-USA) كنتـرل شـد. بـهمنظـور جداسازى جاذب از دستخاه سانتريفوز با دور ...7 بـه مــات 10 min از دستخاه HPLC مدل 4100 Cecil سنجش كرديد. به منظـور افزايش صحت و دقت، تمامى آزمايشات با دو بار تكرار و در مجموع تعداد بrا آزمايش انجام كرديد.

\section{سنتز كاميوزيت كيتوزان- گرافن اكسايد (CGO)}

سنتز گرافن اكسايد (GO) با اسـتفاده از يـودر كرافيـت بـا

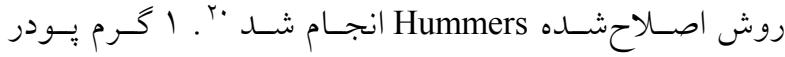

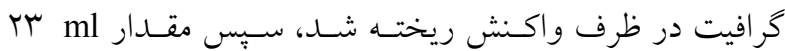
اسيدسولفوريك به ظرف واكنش اضافه كرديد و بـا اسـتفاده از

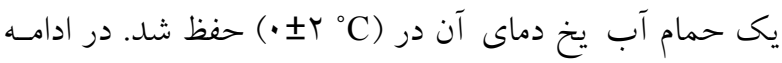

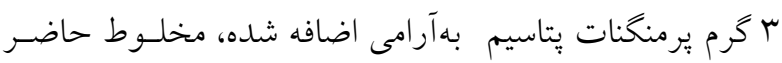

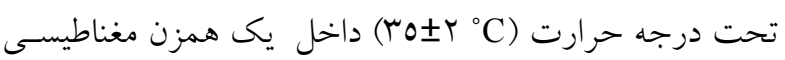
به مدت r ساعت قرار داده شد و به آرامى هم زده شد. سبس مقدارى براكسيد هيدروزن (0 ml) افزوده كرديد تا زمـانى كـه

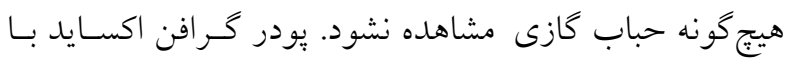
خشك كردن مواد در دماى Co 70 به مدت باى 10 ساعت حاصـل كُديل. سيس محلول حاصله به مدت ب ساعت در دماى اتـاق به وسيله يك حمام اولتراسـونيك بـا فركـانس •7-0.0 هرتـز تحت امواج اولتراسـونيك قــرار كرفـت. نهايتـا يـودر گـرافن 


\section{ارزيابى كارايى كاميوزيت كيتوزان كرافن-اكسايد در حذف آنيلين از محلولهاى آبى}

در معسادلات فـوق R درصــ حسـف آنيلـين، (mg/l) C غلظت اوليـهـ آنيلـين،

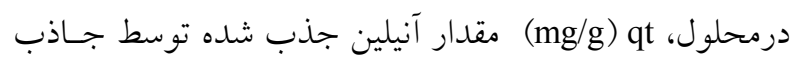

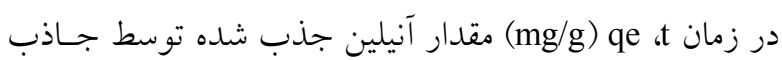

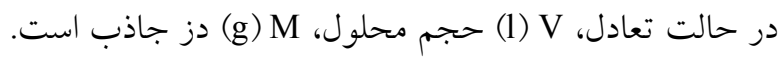

يافتهها

خصوصيات جاذب سنتز شده (CGO) ويزگكى هاى سطحى كرافن اكسـايد و كاميوزيست كيتسوزان

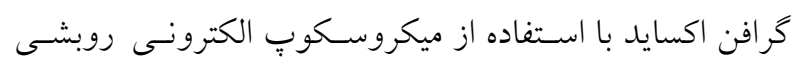
(SEM) دست آمده نشان داد كه كرافن اكسايد داراى سطحى لايهلايـهـ

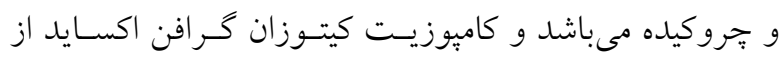

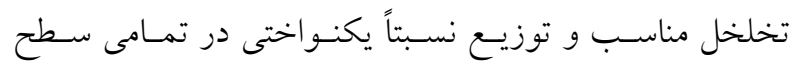

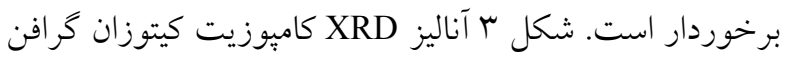

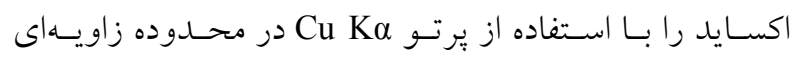

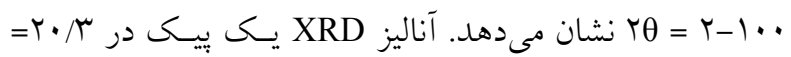

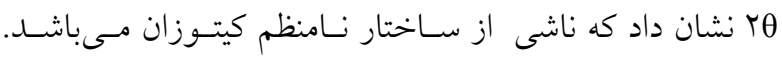

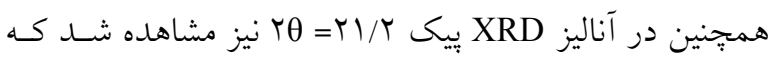

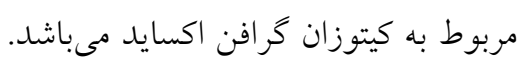

كنتـرل بِديــده جـذب رقـابتى و عوامـل مداخلـه كـر، تمـامى

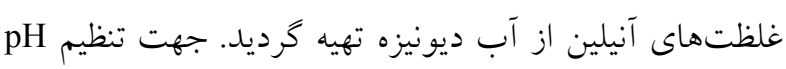

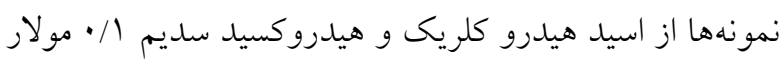

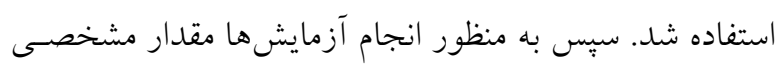

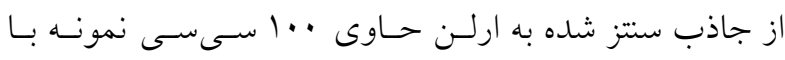

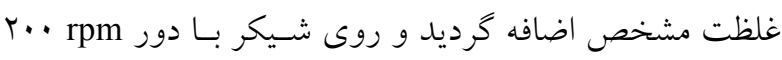

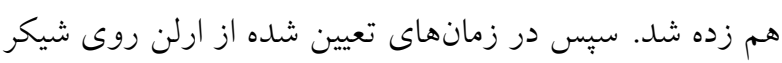

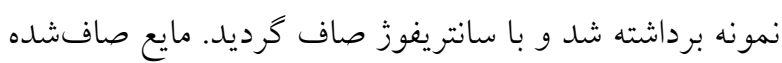

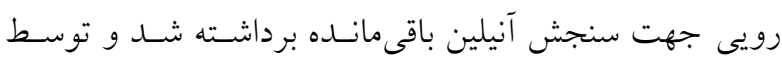
HPLC

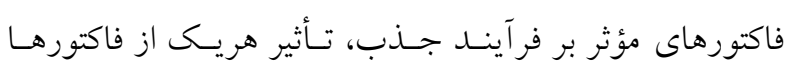

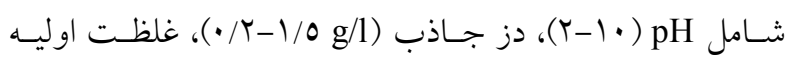
(Y.0.0 مورد مطالعه قرار كرفت.

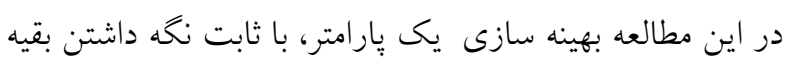

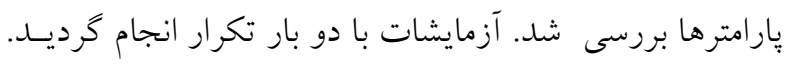

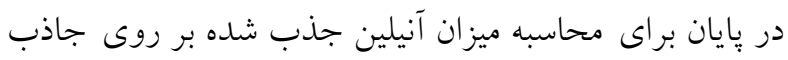

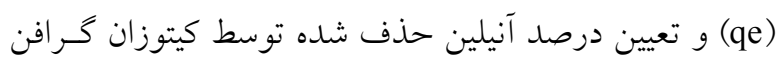
اكسايد از معادلات زير استفاده خرديد: $\boldsymbol{R}=\frac{C_{0}-C_{0}}{C_{0}} \times 100$ رابطه (1) $q_{t}=\frac{\left(C_{0}-C_{t}\right) v}{M}$ رابطه (r) 
فاطمه آزادبخت و همكاران

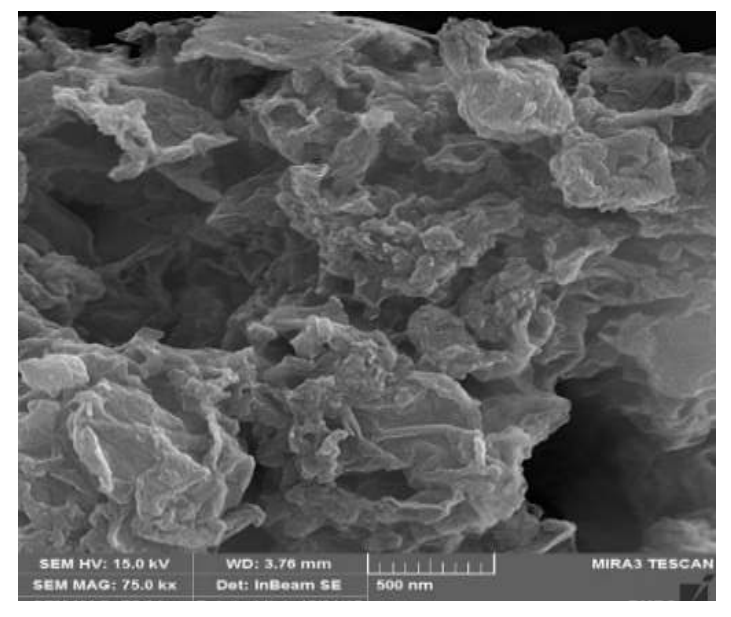

شكل r: تصوير SEM كيتوزان كرافن اكسايد (CGO)

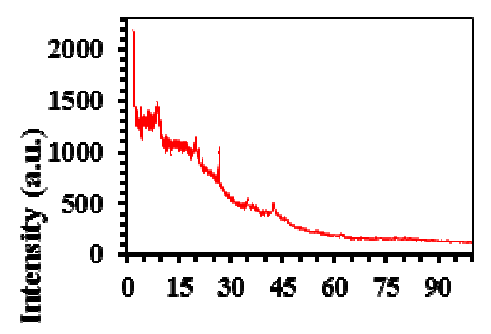

$2 \theta$ (Degree)

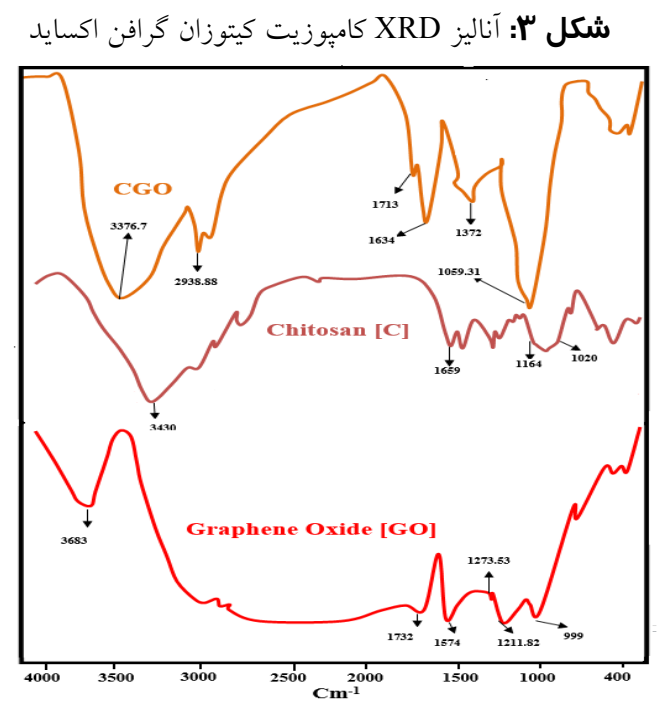

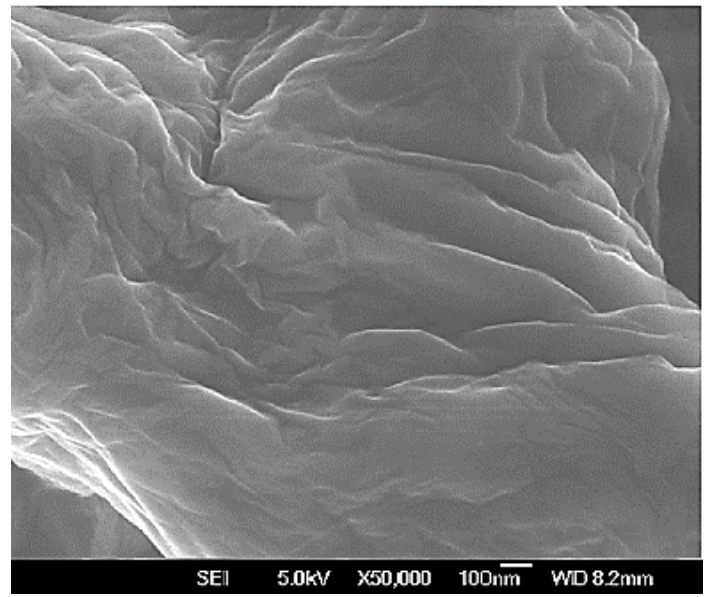

شكل ا: تصوير SEM كرافن اكسايد (GO)

طيفسـنجى (FTIR) كيتـوزان، گــــــ افن اكسـايد، كامبوزيت

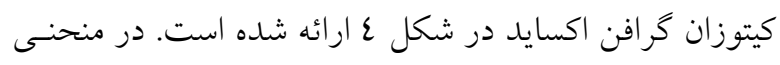
cm و افر FTIR

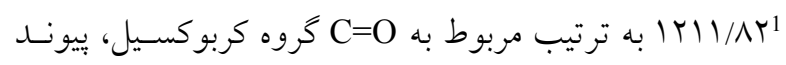

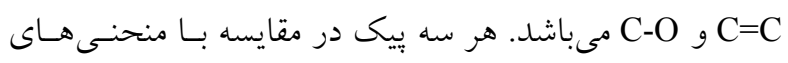

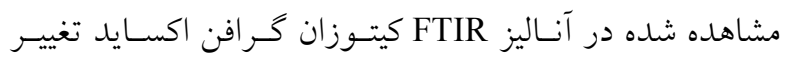

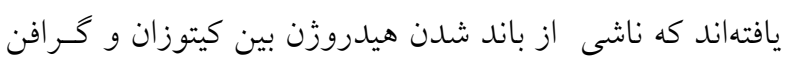

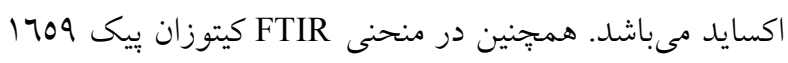

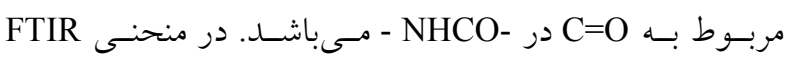

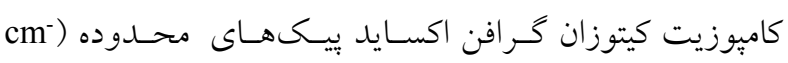

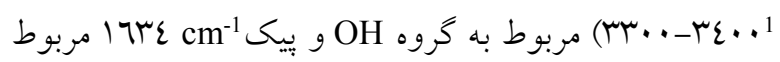

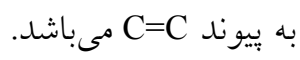

\section{اثر pH محلول}

تأثير pH محلول روى جذب مدلب آنيلين توسط جاذب كيتوزان

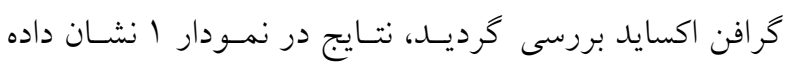

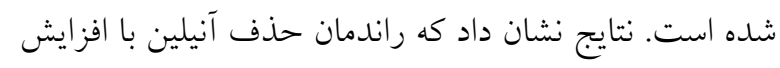

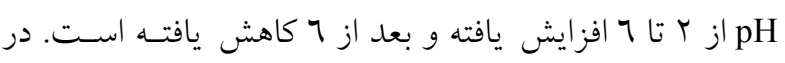

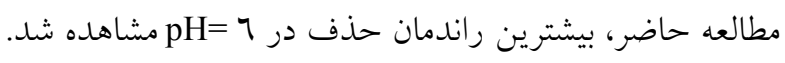




\section{تأثير غلظت اوليه آنيلين}

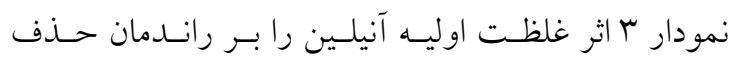

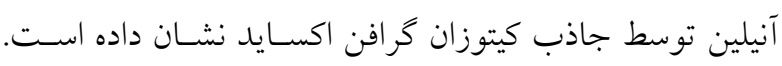

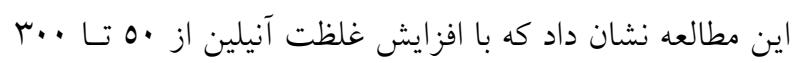

اثر زمان تماس

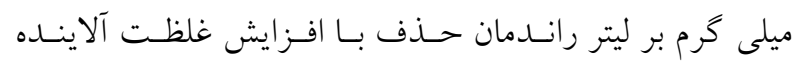

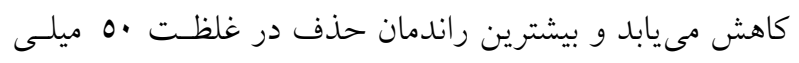

همانكونه كه در نمـودار r مشـاهده مسى شـود، اثـر زمـان

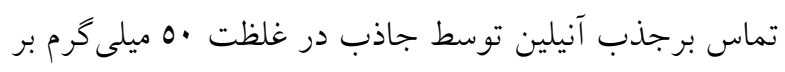

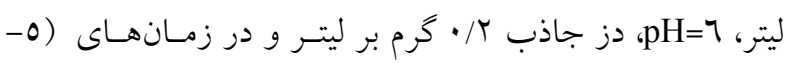

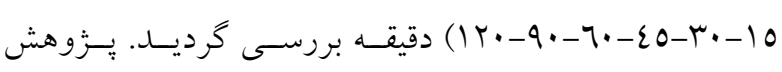

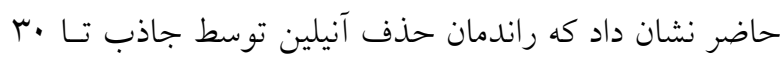

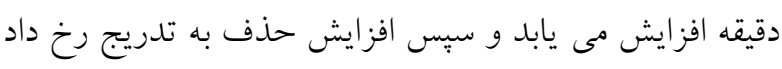
و در زمان •rا ادقيقه به تعادل رسيد.

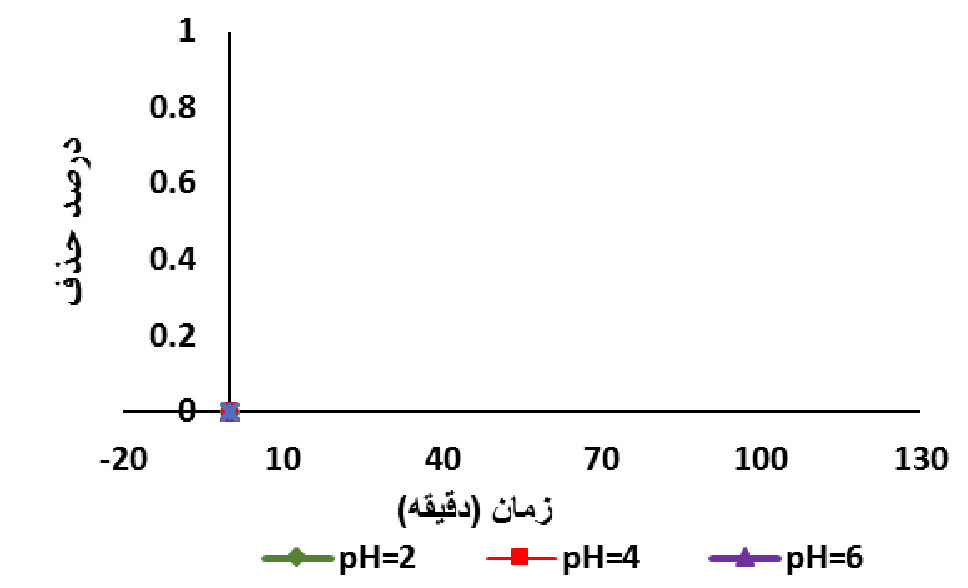

نمودار ا: تأثير pH محلول روى جذب (غلظت •0 ميلى كرم بر ليتر، دز جاذب r/• خرم بر ليتر)

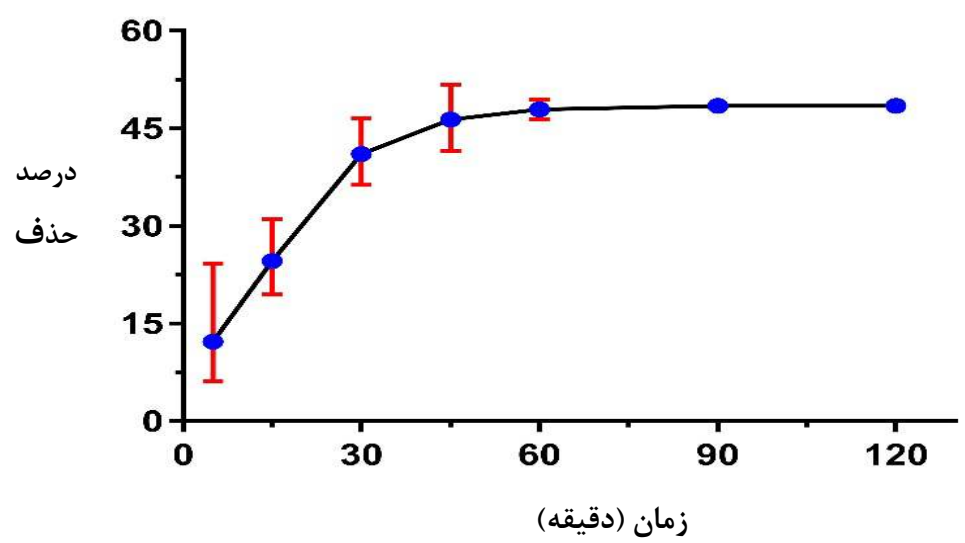




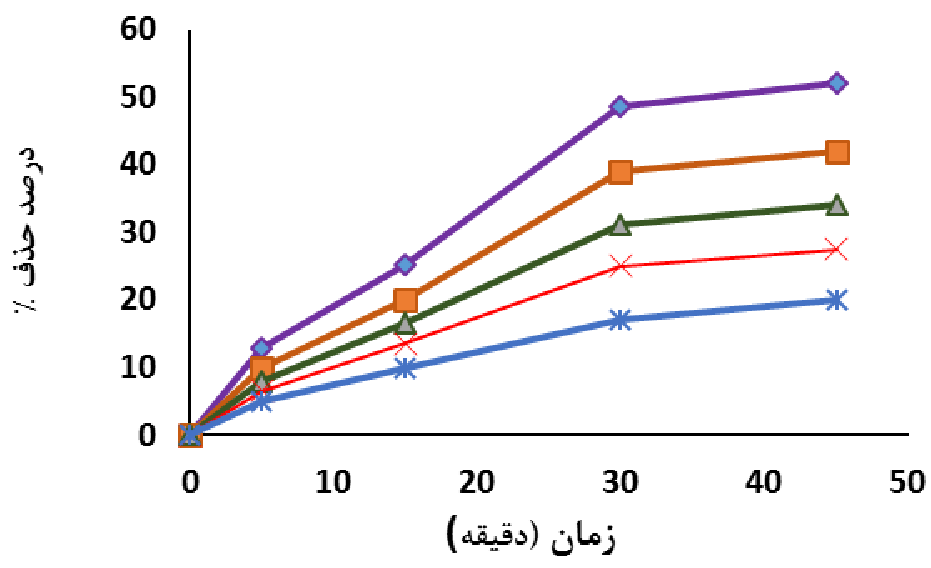

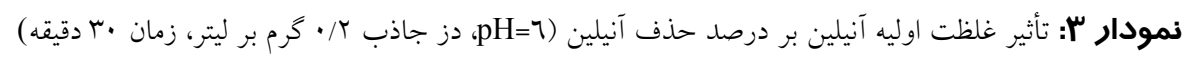

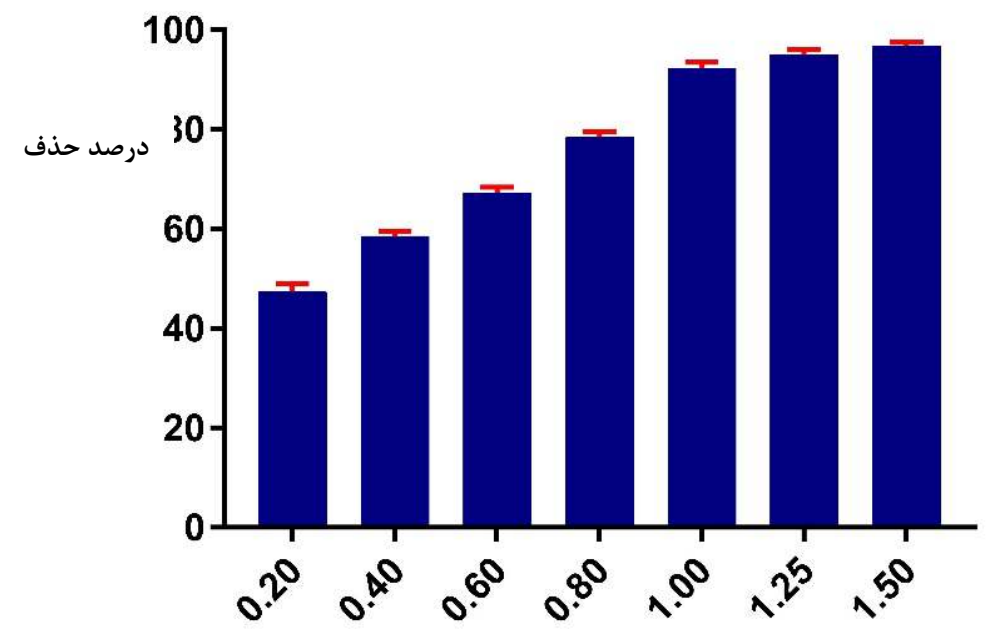

نمودار ع: تأثير زمان تماس روى جذب (pH=7، غلظت •0 ميلى گرم بر ليتر،، دز جاذب ؟/. كرم بر ليتر)

\section{ايزوترم و سينتيك جذب آنيلين در شرايط بهينه}

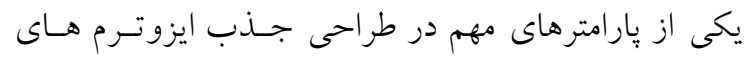
تعادلى مىباشند. در اين مطالعه جهت توصيف تجربى دادههـا

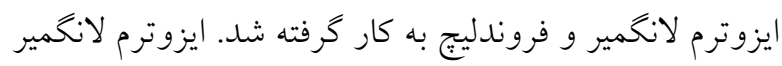

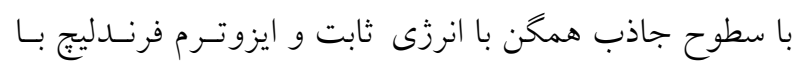

تأثير دوز جاذب

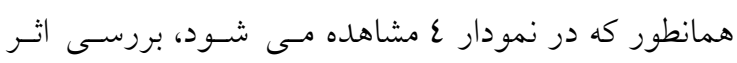

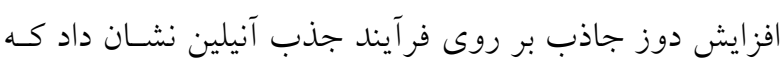

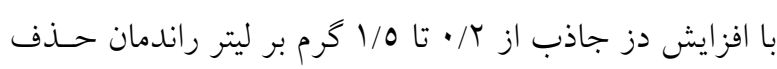

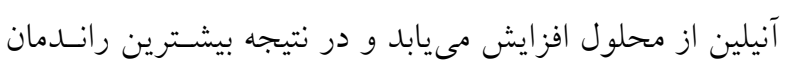

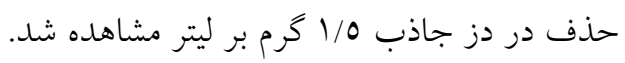




\section{ارزيابى كارايى كاميوزيت كيتوزان كرافن-كسايد در حذف آنيلين از محلولهاى آبى}

pH

به دست آمده برحسب مدلهاى ايزوترم لانخميـر و فرونــليج

در نمودار 0 و 7 ارزيابى كرديدند.
سـطوح نـاهمخن و توزيــع غيريكنو اخــت اسـتوار مسىباشـند.

معادلات ايزوترم لانخمير و فروندليج در جدول r مشاهده مى

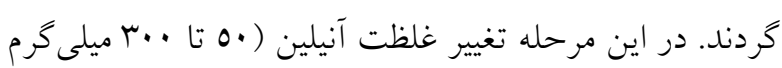

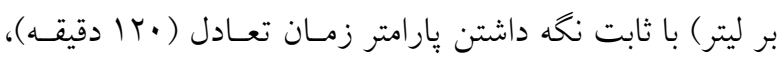

جدول r: معادلات ايزوترم فروندليج و لانخمير

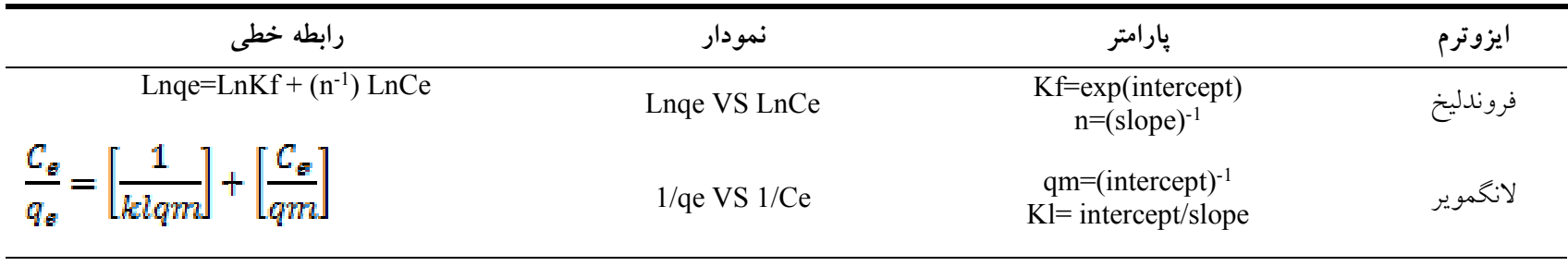

جذب نامطلوب، اخر RL=1 باشد جذب خطى و اخـر

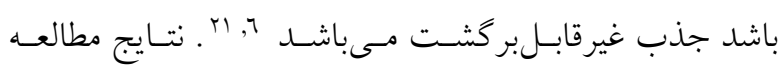
حاضر نشان داد كـه RL كمتـر از ا اسـت و بنـابراين جـــب

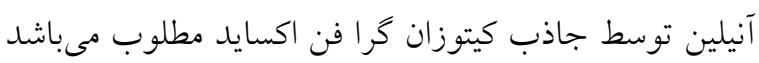

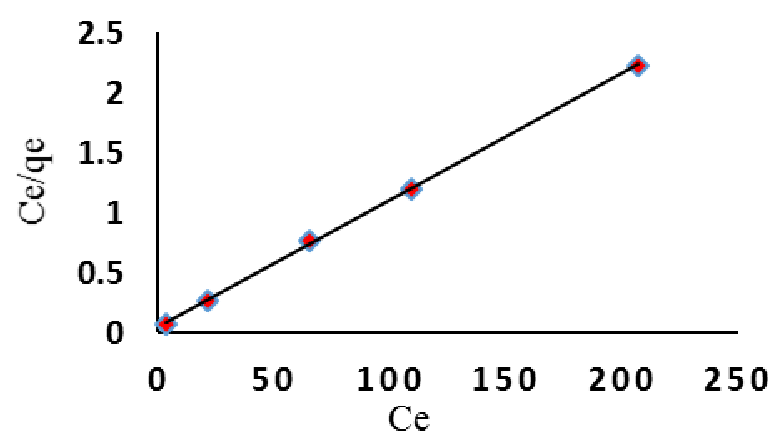

نمودار و: ايزوترم جـذب مـدل لانخمـوير بـراى جـــب آنيلـين توسط كيتوزان كرافن اكسايد

جهت ارزيابى عملكـرد جـاذب و مكانيسـم جـذب از دو

مدل سينتيك درجه اول و دوم استفاده شد. در جدول ع مـدل هاى سنتيكى و تعادلى مورد استفاده براى جذب آنيلـين ارائـه. شده است. در اين جدول ( qt و و qe مقدار ماده جـــب

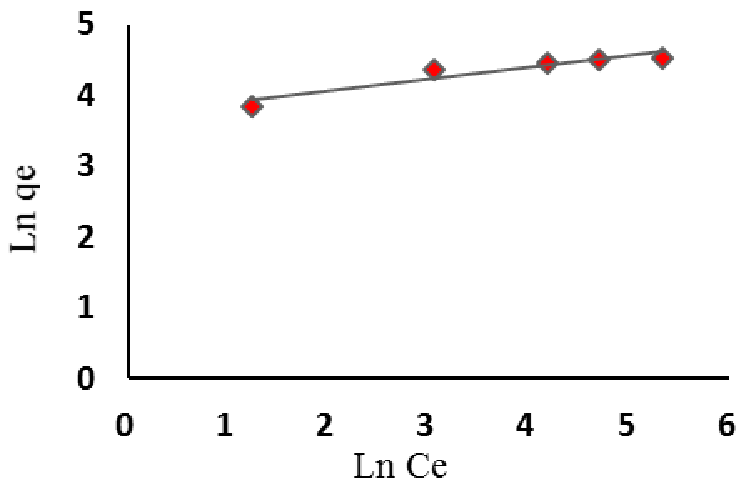

نمودار ذ: ايزوترم جذب مــل فرونــليج بـراى جـذب آنيلـين توسـط

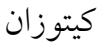

\section{كرافن اكسايد}

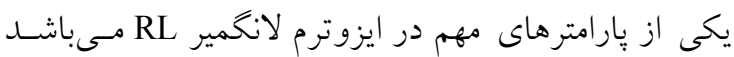

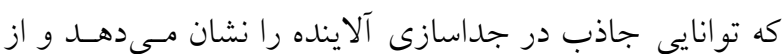
رابطه زير محاسبه مي كردد:

$$
R L=\frac{1}{1+b C_{0}}
$$

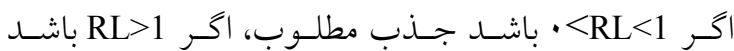




$$
\text { فاطمه آزادبخت و همكاران }
$$

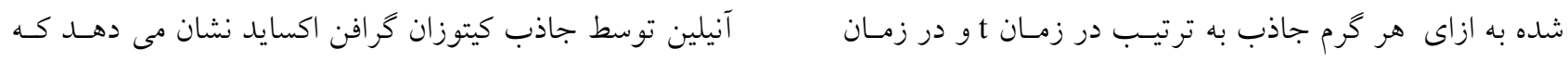

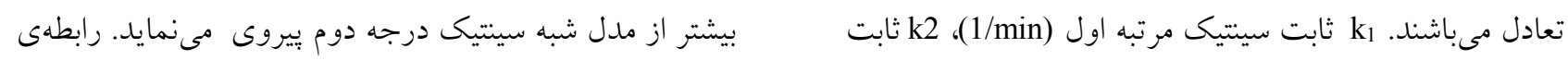

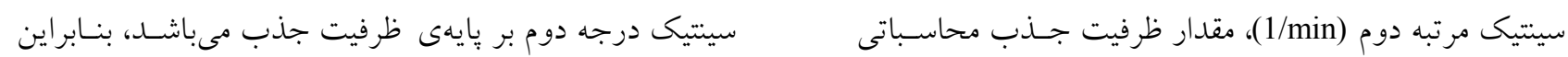

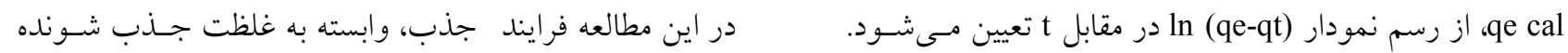

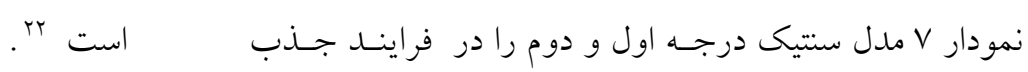

\begin{tabular}{|c|c|c|}
\hline ايزوترم & بارامتر & جذب \\
\hline فروندليخ & $\begin{array}{l}\mathrm{R}^{2} \\
1 / \mathrm{n} \\
\mathrm{Kf}\end{array}$ & $\begin{array}{c}\cdot / 9 \\
\cdot / 17 \\
1\end{array}$ \\
\hline لانحمير & $\begin{array}{l}\mathrm{R}^{2} \\
\mathrm{RL} \\
\mathrm{qm}\end{array}$ & $\begin{array}{c}\cdot / 9997 \\
\cdot / \cdot M 1-\cdot / \cdot 10 \\
9 \varepsilon / M 1\end{array}$ \\
\hline
\end{tabular}

\begin{tabular}{|c|c|}
\hline \multicolumn{2}{|c|}{ بدول 0: بارامترهاى سينتيكى فرايند جذب آنيلين توسط CGO } \\
\hline جذب شونده & مدل سينتيك \\
\hline \multicolumn{2}{|c|}{ شبه درجه اول } \\
\hline $7 r / 0$ & qe, cal (mg/g) \\
\hline .10770 & $\mathrm{R}^{2}$ \\
\hline$\cdot / \cdot\{\rceil$ & $\mathrm{K}_{1}$ \\
\hline \multicolumn{2}{|c|}{ شبه درجه دوم } \\
\hline$O V / \Lambda \cdot$ & qe, cal (mg/g) \\
\hline$\cdot / 9 \vee 99$ & $\mathrm{R}^{2}$ \\
\hline$\cdot 1 \cdots 91$ & $\mathrm{~K}_{2}$ \\
\hline
\end{tabular}

qe $\cdot \exp =\{9 / 7\rceil$ 

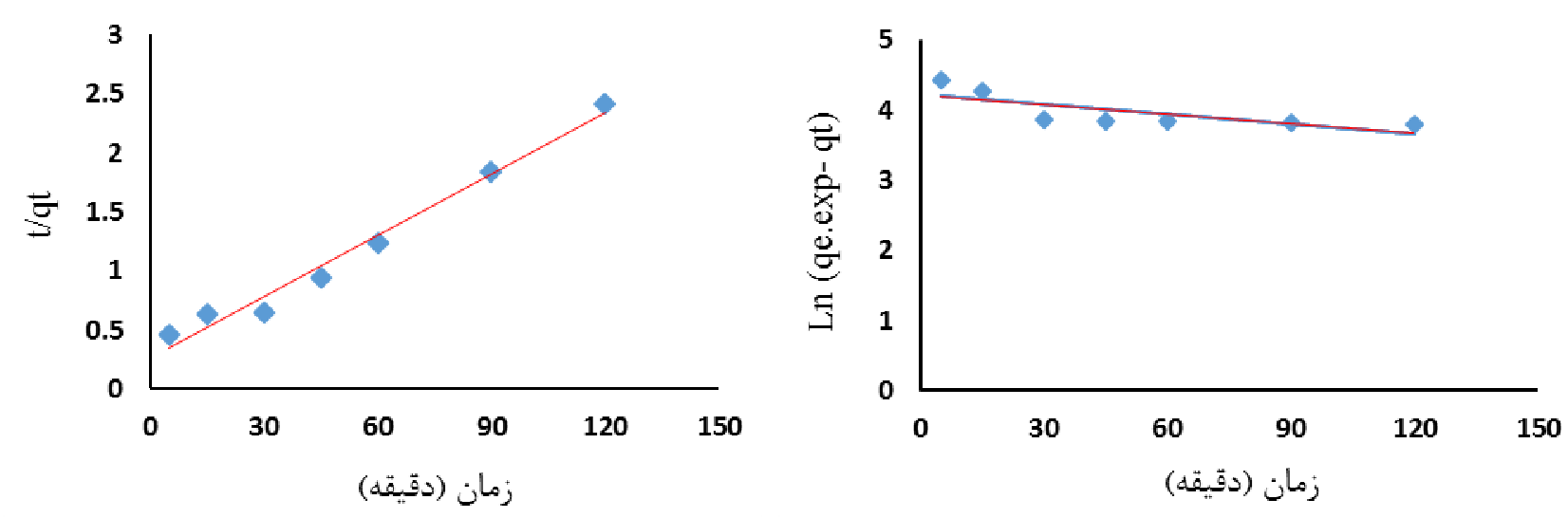

نمودار V: مدل سيتتيك شبه درجه اول و دوم جذب آنيلين توسط جاذب كيتوزان كرافن اكسايد

آنتابلى هH منفى و آنترويى استاندارد SS مثبـت وانـرزى آزاد

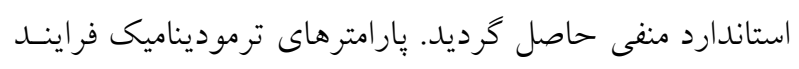

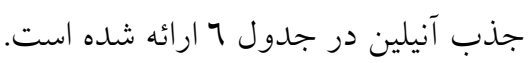

ترموديناميك جذب آنيلين در شرايط بهينه

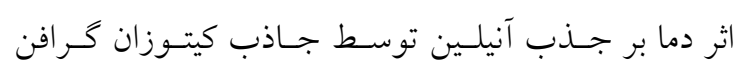

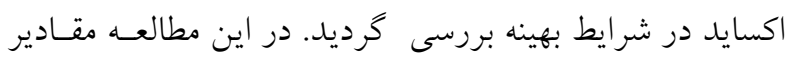

جدول 9: بارامترهاى ترموديناميك فرايند جذب آنيلين توسط CGO

\begin{tabular}{|c|c|c|c|c|}
\hline $\begin{array}{c}\Delta S \\
(\mathrm{KJ} / \mathrm{molk})\end{array}$ & $\begin{array}{c}\Delta \mathbf{H} \\
(\mathrm{KJ} / \mathrm{mol})\end{array}$ & $\begin{array}{c}\Delta \mathbf{G} \\
(\mathrm{KJ} / \mathrm{mol})\end{array}$ & دما ("olo & يارامتر \\
\hline \multirow[t]{3}{*}{.110} & $-r \Lambda / \cdot r \varepsilon$ & $-T / \Gamma \circ \varepsilon \cdot 7$ & rar & 1 \\
\hline & & $-9 / 00\{19$ & $r \cdot r$ & r \\
\hline & & $-I T / V \varepsilon \wedge V$ & חצr & $r$ \\
\hline
\end{tabular}

جدولV: كارايى حذف آنيلين با جاذب احيا شده با استفاده از HCL و NaOH در مر زمان •r دوقيقه

\begin{tabular}{|c|c|c|}
\hline درصد واجذب NaOH & درصد واجذب HCL & 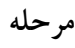 \\
\hline$\sum 1 / T_{0}$ & $\Lambda \varepsilon / T_{0}$ & 1 \\
\hline ו וT/M & VO/AT & r \\
\hline$r V / l$. & WN/TO & r \\
\hline TO/VT & $O V / \varepsilon 0$ & $\varepsilon$ \\
\hline$r M / T V$ & $00 / 99$ & 0 \\
\hline
\end{tabular}

توسط جاذب كيتوزان خـرافن اكسـايد بعـــ از 0 مرحلـه احيـا احياء جذب

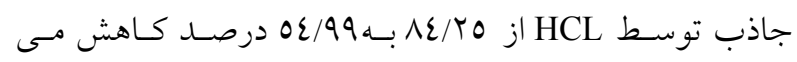
جدول كارايى حذف آنيلين با جاذب احيا شده با استفاده

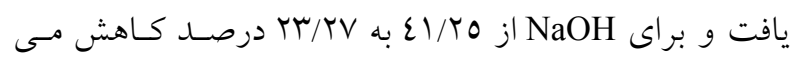
از

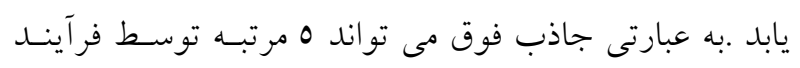

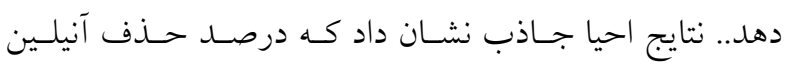




\section{اثر زمان تماس}

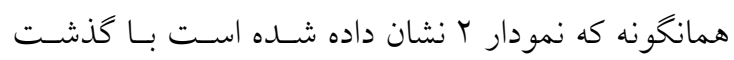

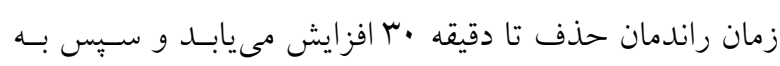

بحث

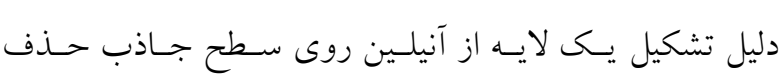

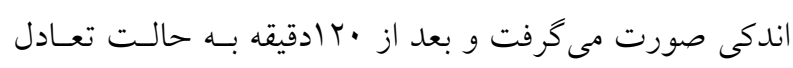

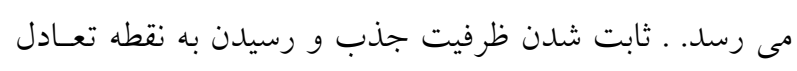

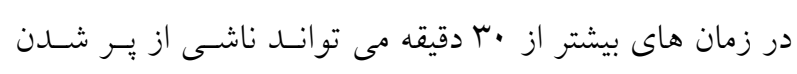

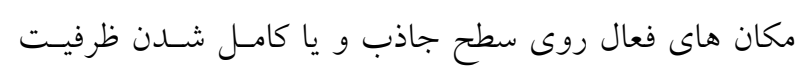

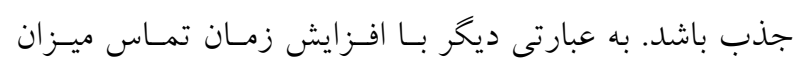

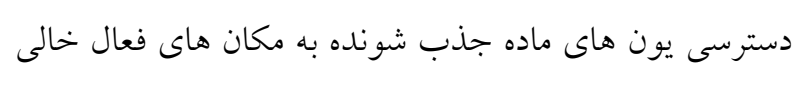

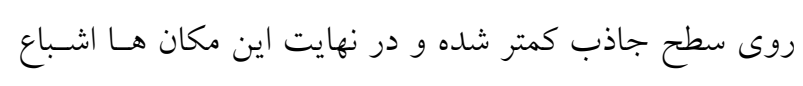

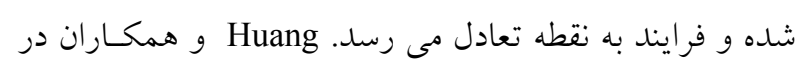
تحقيق حذف آنيلين و يون كروم توسط كاميوزيت كربن فعـال

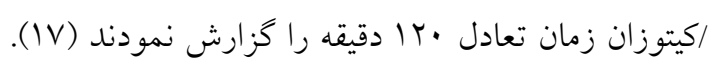

\section{اثر غلظت هاى مختلف آنيلين}

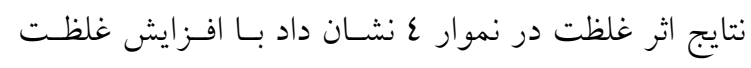

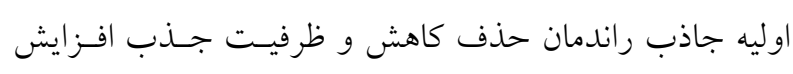

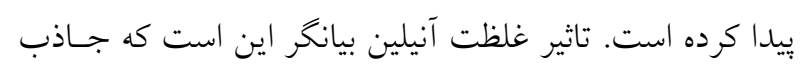
داراى مكان هاى جذب مشخص و محدودى مى باشد كـه در

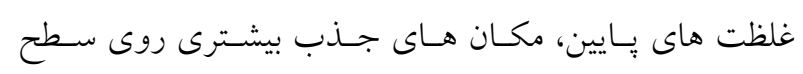

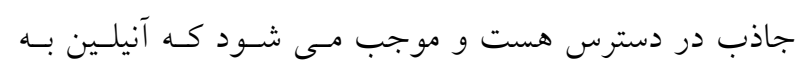

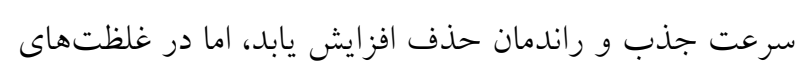

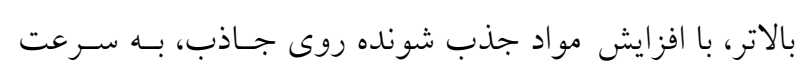
مكان هاى جذب سـطوح بـالايى روى جـاذب اشـباع شــده و راندمان حذف ماده ى جاذب كاهش مى يابد 7 . همجنين نتايج

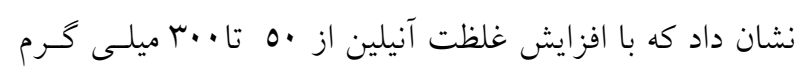

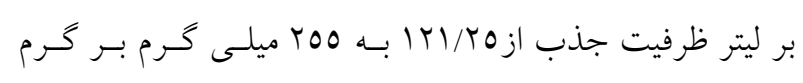

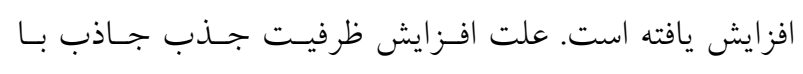

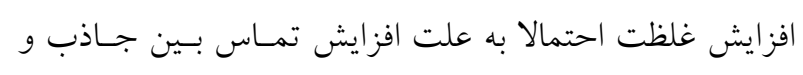

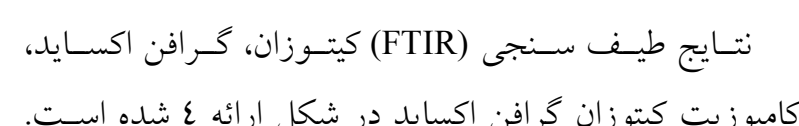

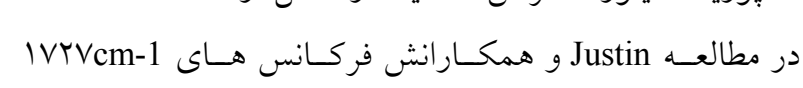
مربوط به C=O و C C

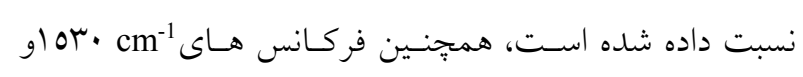

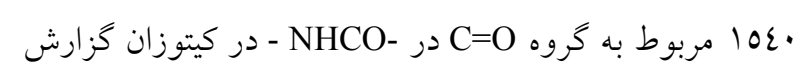

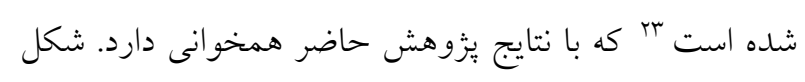

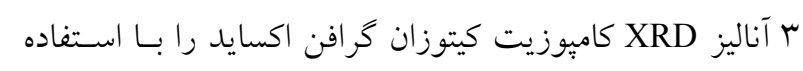

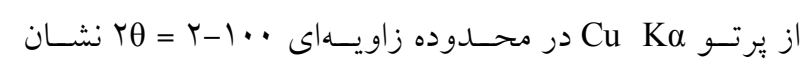

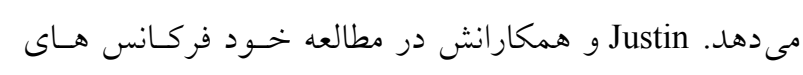
م

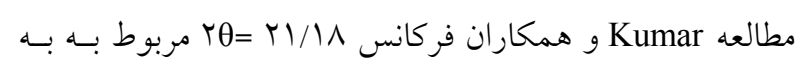

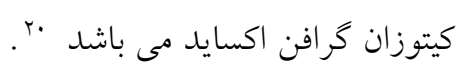

اثر pH محلول

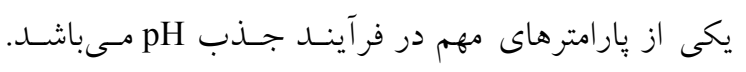

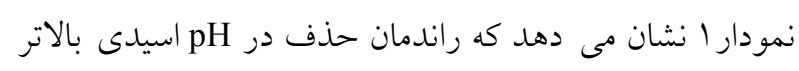

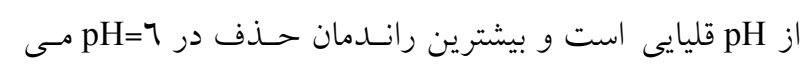
باشد. علت كاهش راندمان حذف در pH هاى بيشتر بــــ دليـل

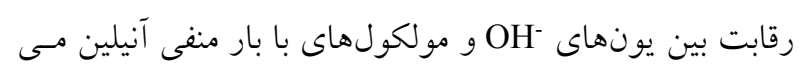

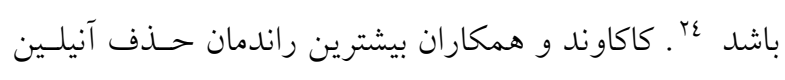

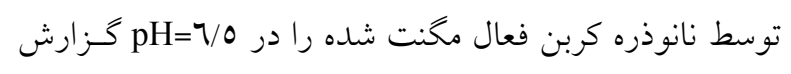

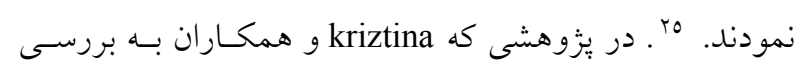
ارتباط بين pH و ميزان جذب آنيلين و فنول توسط كربن فعال

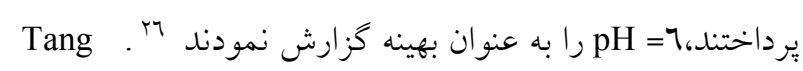

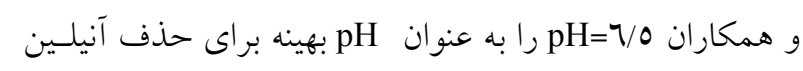

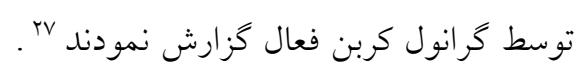


ارزيابى كارايى كاميوزيت كيتوزان كرافن-اكسايد در حذف آنيلين از محلولهاى آبى

داده با افزايش دوز جاذب، راندمان حذف افزايش مى يابد بان.

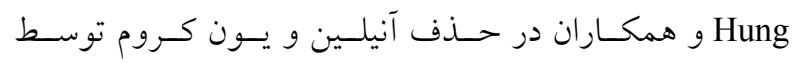

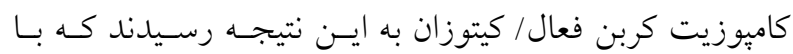

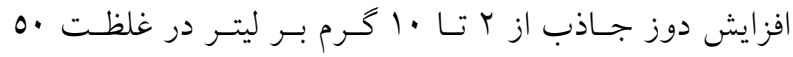

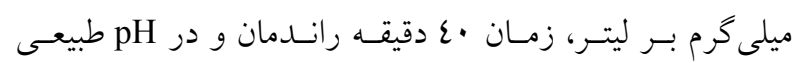
راندمان حذف افزايش مى يابد 10.

\section{ايزوترم و سينتيك جذب آنيلين}

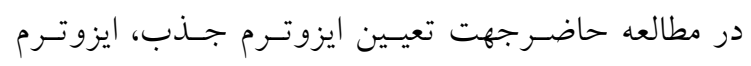

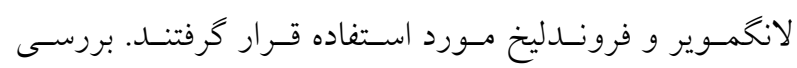

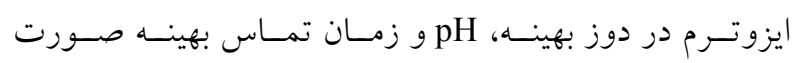

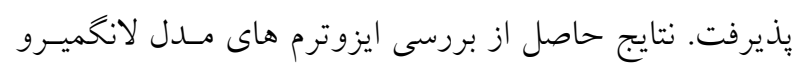

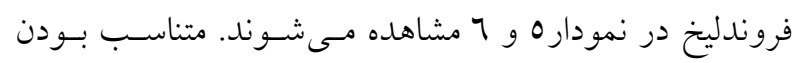

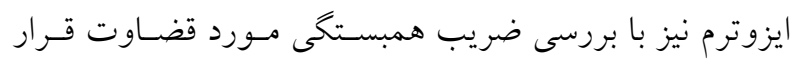

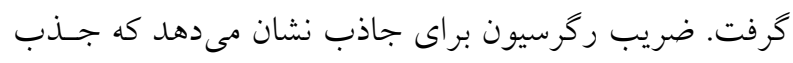

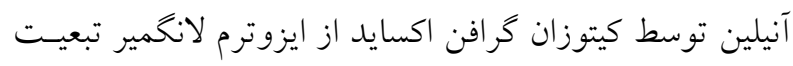

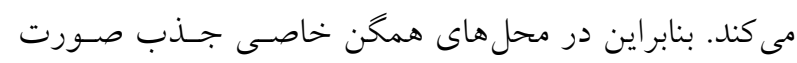

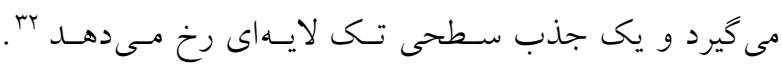

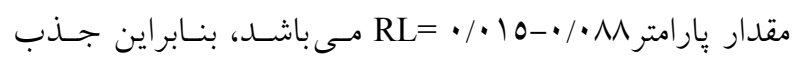
مطلوب است. نتايج يزوهش Ruihua و همكاران نشان كردنــ بـاند حذف همزمان آنيلين و يـون كـروم توسط كاميوزيـت كـربن

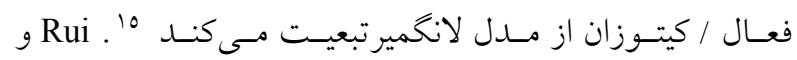

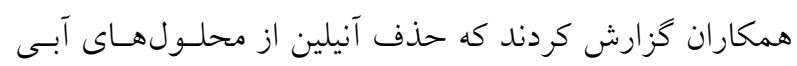

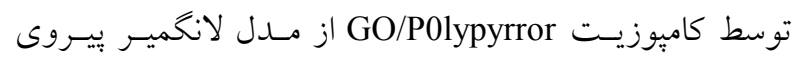

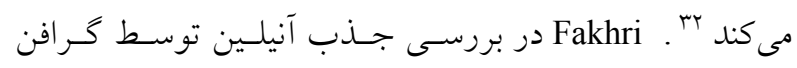

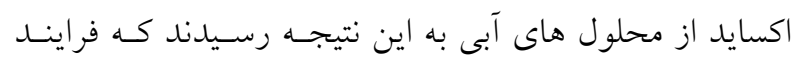

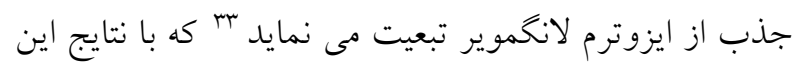

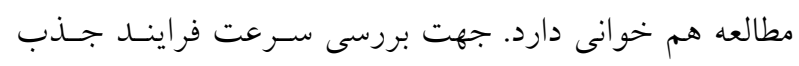

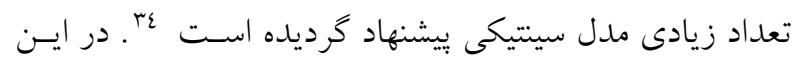

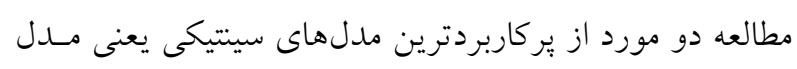

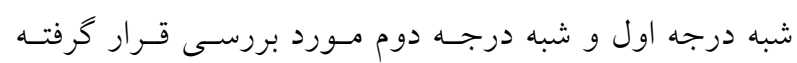

جذب شونده مى باشد ^^. عامـل ديخـــى كـه باعـث افز ايش

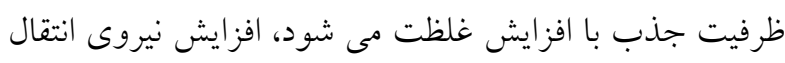

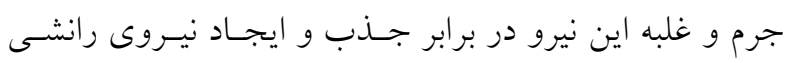

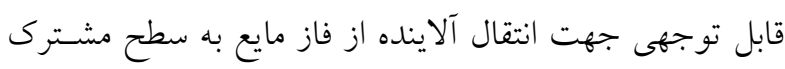

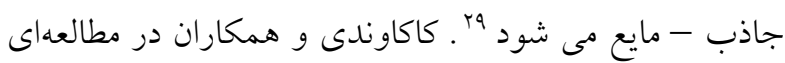

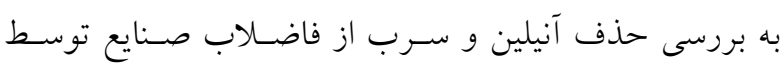

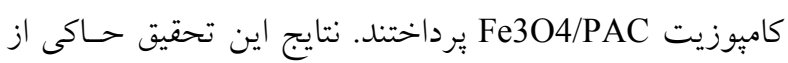

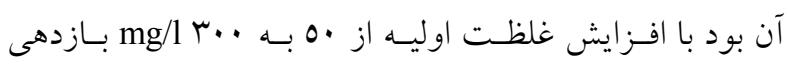

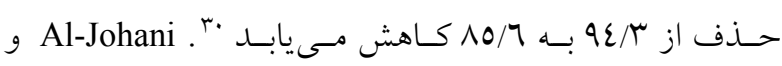

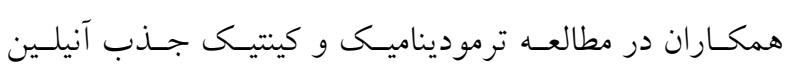

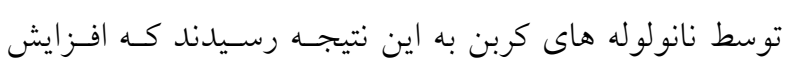

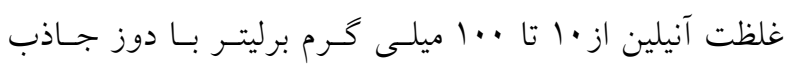

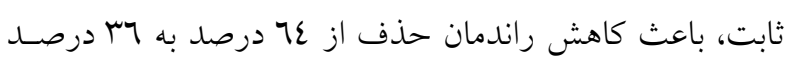

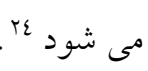

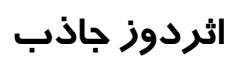

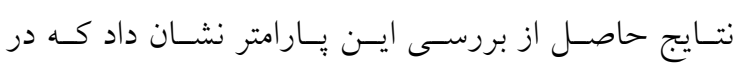

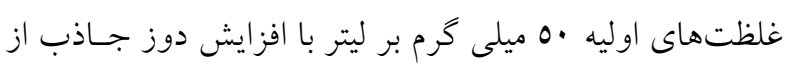

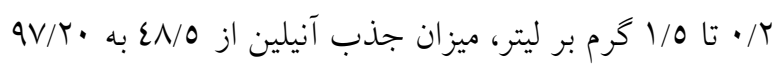

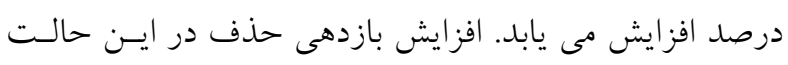

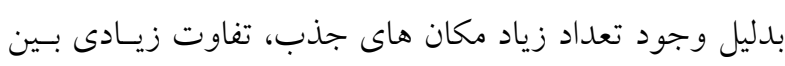

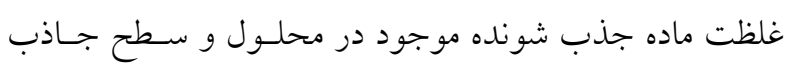

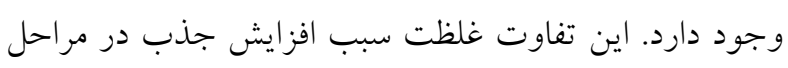

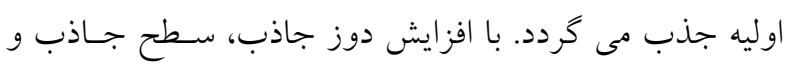

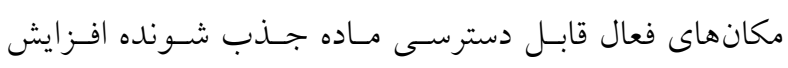

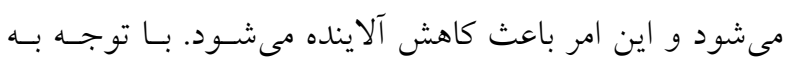

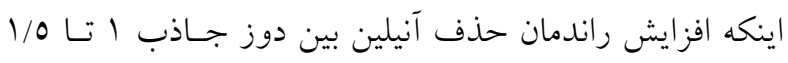

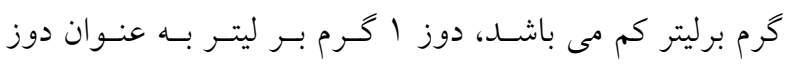

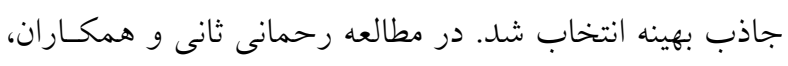

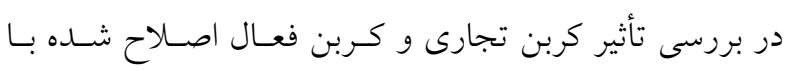

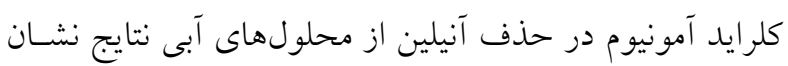


فاطمه آزادبخت و همكاران

خودبه خودى مى باشد. با توجه به اينكـهـ مقــادير كH كمتـر از

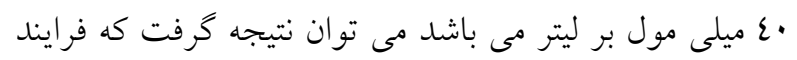

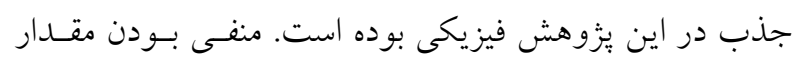

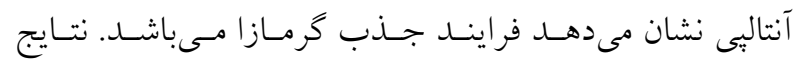

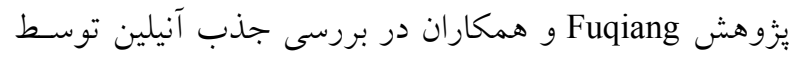

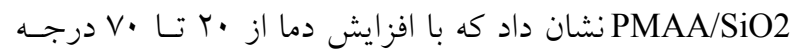

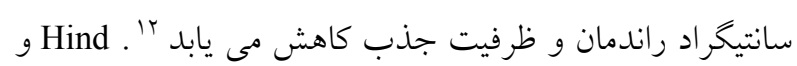

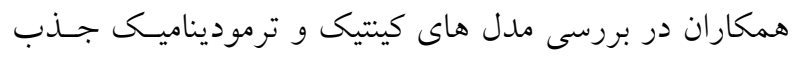

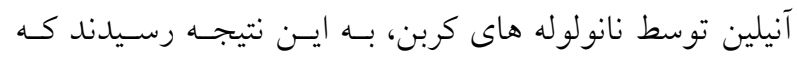

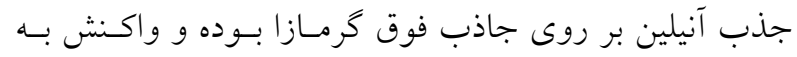

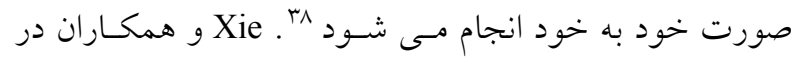

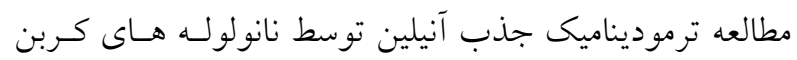

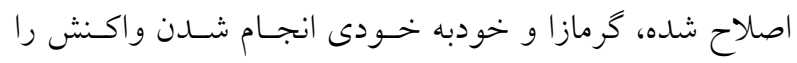

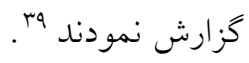

\section{تفسيرنتايج قابليت استفاده مجدد از جاذب}

در اين يُزوهش مطابق بررسى ساير مطالعات از دو محلول

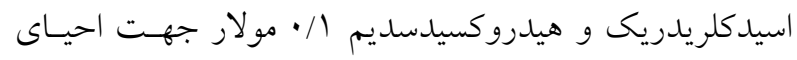

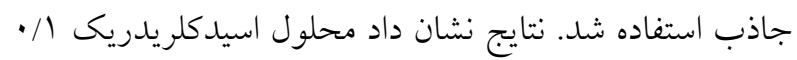

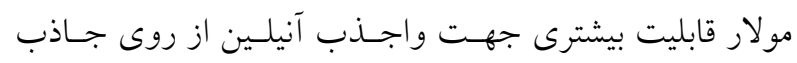

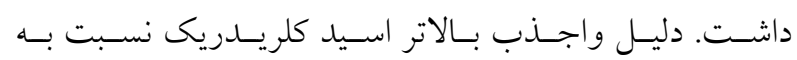

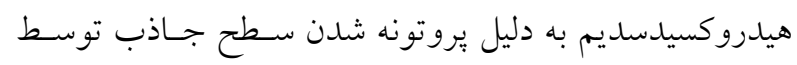

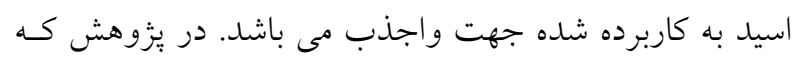
Cechinel

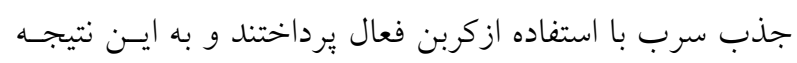

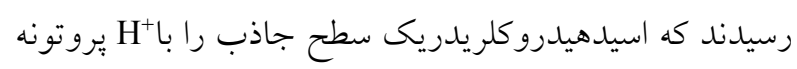

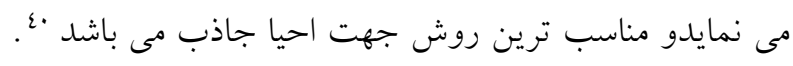

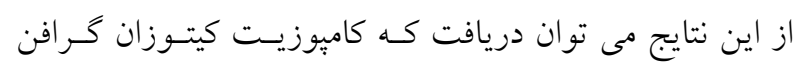

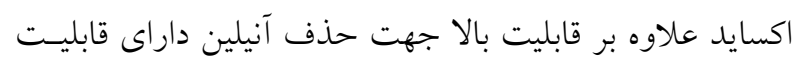

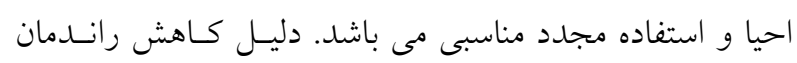

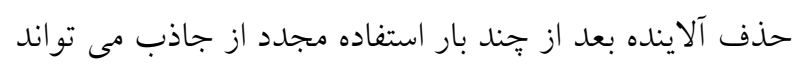

است. مدل سينتيك شبه درجه دوم نشان مى دهد كـه سـرعت

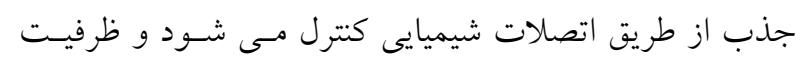

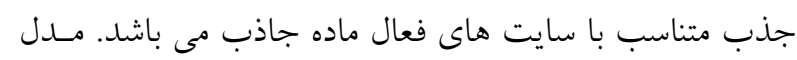

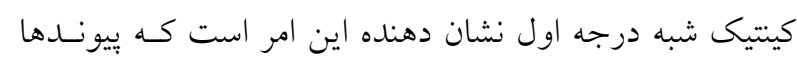

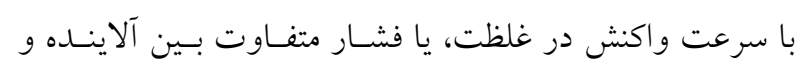
سطح جاذب بستخى دارد. نتايج حاكى از آن است كه بالاترين همبستخى (R) مربوط به مدل كينتيكى شـبه درجسه دوم بـود.

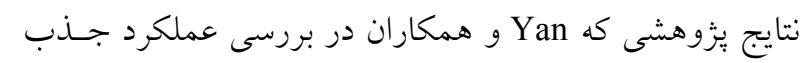

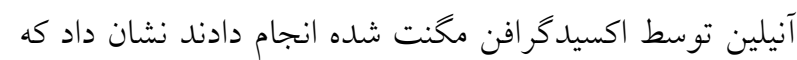

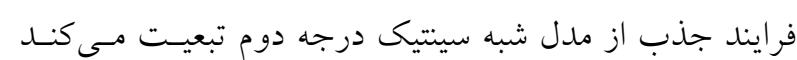

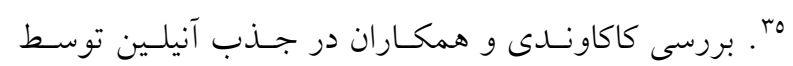

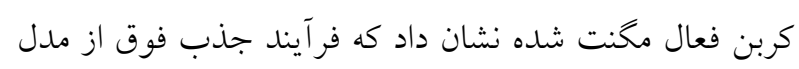

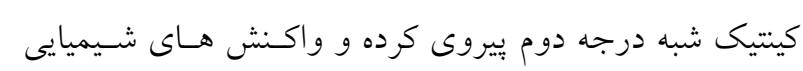

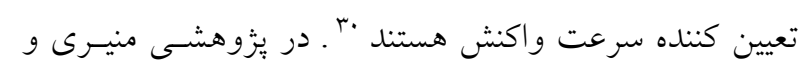

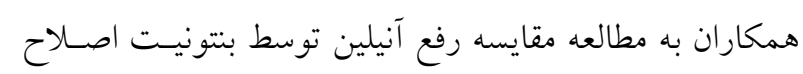

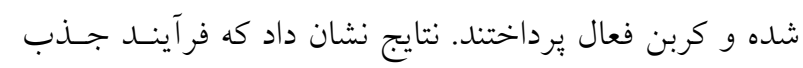

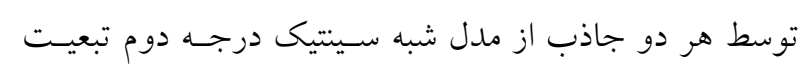

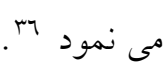

\section{ترموديناميك جذب آنيلين در شرايط بهينه}

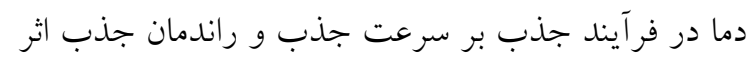

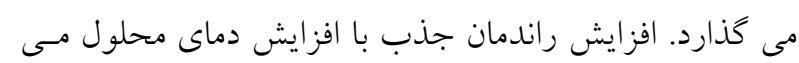
تواند بدليل افزايش برخوردهاى موثر بين ماده شونده و جاذب راذب دمان

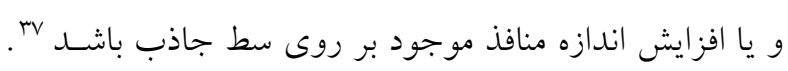
مطالعه جذب جهت بررسى تاثير دما بر راندمان حذف آنيلسين

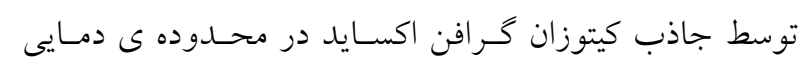

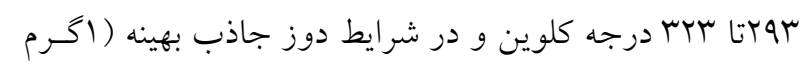

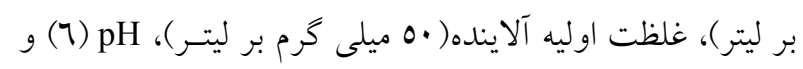

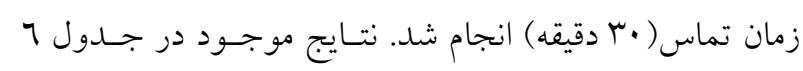

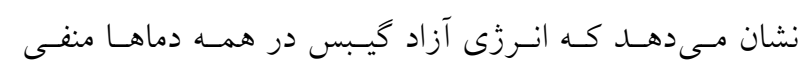

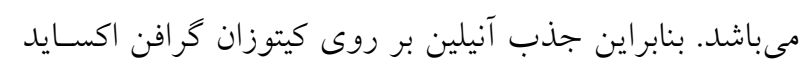




$$
\begin{aligned}
& \text { اين مقاله حاصل هاياننامه مقطع كارشناسى ارشد مهندسى }
\end{aligned}
$$

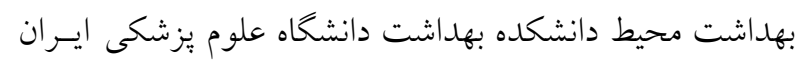

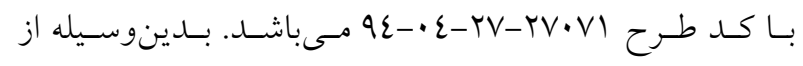

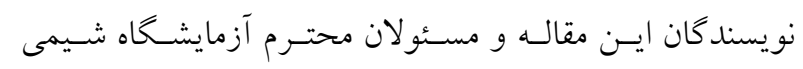

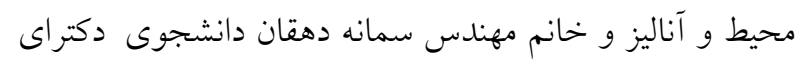

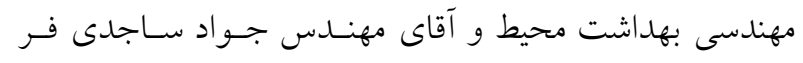

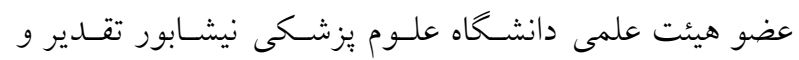

$$
\begin{aligned}
& \text { تشكر مىشود. }
\end{aligned}
$$$$
\text { ارزيابى كارايى كامِيوزيت كيتوزان كرافن-كسايد در حذف آنيلين از محلولهاى آبى }
$$

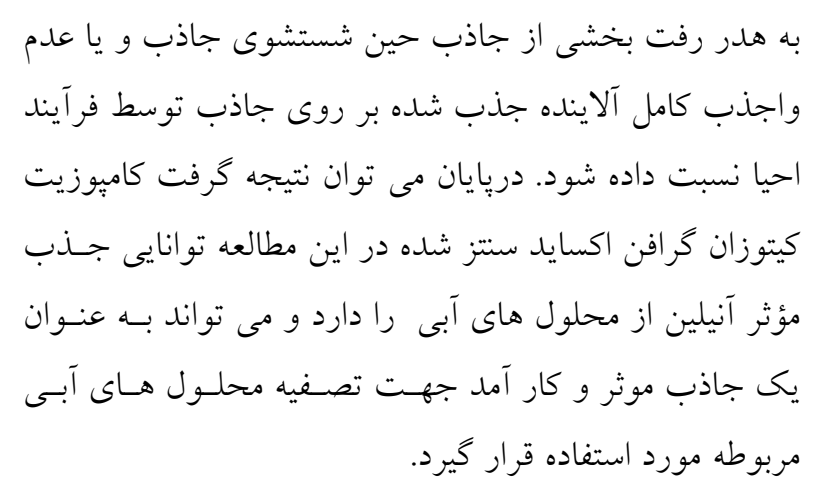$$
\text { تشكر قدردانى }
$$

\section{References}

1. Gao D-W, Hu Q, Pan H, et al. High-capacity adsorption of aniline using surface modification of lignocellulose-biomass jute fibers. Bioresource Technol 2015;193: 507-12.

2. Niu J, Conway BE. Adsorptive and electrosorptive removal of aniline and bipyridyls from waste-waters. J Electroanal Chem 2002;536(1): 83-92.

3. Rappoport Z. The chemistry of anilines: John Wiley \& Sons; 2007.

4. Anotai J, Lu M-C, Chewpreecha P. Kinetics of aniline degradation by Fenton and electro-Fenton processes. Water Res 2006;40(9): 1841-7.

5. Han $\mathrm{Y}$, Quan $\mathrm{X}$, Chen $\mathrm{S}$, et al. Electrochemically enhanced adsorption of aniline on activated carbon fibers. Sep Purif Technol 2006;50(3): 365-72.

6. Wu G-Q, Zhang X, Hui H, et al. Adsorptive removal of aniline from aqueous solution by oxygen plasma irradiated bamboo based activated carbon. Chem Eng J 2012;185: 201-10.

7. Mansoury M, Godini H, Shams Khorramabadi G. Photocatalytic removal of natural organic matter from aqueous solutions using zinc oxide nanoparticles immobilized on glass. Iran J Health Environ 2015;8(2): 181-90. (In Persian)

8. Fairfax R. OSHA Compliance Issues: Making Sense of OSHA Standards with Medical Requirements: Part I. Appl Occup Environm Hyg 1998;13(3): 144-8.

9. Barbier J, Oliviero L, Renard B, Duprez D. Catalytic wet air oxidation of ammonia over $\mathrm{M} / \mathrm{CeO} 2$ catalysts in the treatment of nitrogen-containing pollutants. Catal Today 2002;75(1): 29-34.

10. Jiang Y, Pétrier C, Waite TD. Effect of $\mathrm{pH}$ on the ultrasonic degradation of ionic aromatic compounds in aqueous solution. Ultrason Sonochem 2002;9(3): 163-8.

11. Pithan F, Staudt-Bickel C, Lichtenthaler R. Synthesis of highly fluorinated copolyimide membranes for the removal of high boiling organics from process water and wastewater by pervaporation. Desalination 2002;148(1): 1-4.

12. An F, Feng X, Gao B. Adsorption property and mechanism of composite adsorbent PMAA/SiO 2 for aniline. J Hazard Mater 2010;178(1): 499-504.

13. Moussavi G, Hosseini H, Alahabadi A. The investigation of diazinon pesticide removal from contaminated water by adsorption onto $\mathrm{NH} 4 \mathrm{Cl}-$ induced activated carbon. Chem Eng J 2013;214: 1729.

14. Kakavandi B, Jonidi A, Rezaei R, et al. Synthesis and properties of $\mathrm{Fe} 3 \mathrm{O}$ 4-activated carbon magnetic nanoparticles for removal of aniline from aqueous solution: equilibrium, kinetic and thermodynamic studies. J Environ Health Sci Eng 2013;10(1): 1 .

15. Huang R, Yang B, Liu Q, Liu Y. Simultaneous adsorption of aniline and $\mathrm{Cr}$ (VI) ion by 2014;131(4).

16. Badi MY, Azari A, Esrafili A, et al. Performance evaluation of magnetized multiwall carbon nanotubes by iron oxide nanoparticles in removing fluoride from aqueous solution. J Mazandaran Univ Med Sci 2015;25(124): 128-42. (In Persian)

17. Sitko R, Zawisza B, Malicka E. Graphene as a new sorbent in analytical chemistry. TrAC Trends in Anal Chem 2013;51: 33-43. activated carbon/chitosan composite. J Appl Polym Sci 


\section{فاطمه آزادبخت و همكاران}

18. Bustos-Ramírez K, Martínez-Hernández AL, Martínez-Barrera G, et al. Covalently bonded chitosan on graphene oxide via redox reaction. Mater 2013;6(3): 911-26.

19. Zhou M, Martin G, Taha S, Sant'Anna F. Adsorption isotherm comparison and modelling in liquid phase onto activated carbon. Water Res 1998;32(4): 1109-18.

20. Kumar S, Koh J. Physiochemical and optical properties of chitosan based graphene oxide bionanocomposite. Int J Biol Macromol 2014;70: 55964.

21. Foo K, Hameed B. Insights into the modeling of adsorption isotherm systems. Chem Eng J 2010;156(1): 2-10.

22. Gobi K, Mashitah M, Vadivelu V. Adsorptive removal of methylene blue using novel adsorbent from palm oil mill effluent waste activated sludge: equilibrium, thermodynamics and kinetic studies. Chem Eng J 2011;171(3): 1246-52.

23. Justin R, Chen B. Characterisation and drug release performance of biodegradable chitosangraphene oxide nanocomposites. Carbohydrate polym 2014;103: 70-80.

24. Al-Johani H, Salam MA. Kinetics and thermodynamic study of aniline adsorption by multiwalled carbon nanotubes from aqueous solution. $\mathrm{J}$ Colloid Interf Sci 2011;360(2): 760-7.

25. Xie J, Meng W, Wu D, et al. Removal of organic pollutants by surfactant modified zeolite: Comparison between ionizable phenolic compounds and non-ionizable organic compounds. J Hazard Mater 2012;231: 57-63.

26. László K, Tombácz E, Novák C. pHdependent adsorption and desorption of phenol and aniline on basic activated carbon. Colloids Surf A Physicochem Eng Asp 2007;306(1): 95-101.

27. Tang B, Lin Y, Yu P, Luo Y. Study of aniline/ $\varepsilon$-caprolactam mixture adsorption from aqueous solution onto granular activated carbon: kinetics and equilibrium. Chem Eng J 2012;187: 69-78.

28. Kumar M, Tamilarasan R. Modeling studies: Adsorption of aniline blue by using Prosopis Juliflora carbon/Ca/alginate polymer composite beads. Carbohydrate Polym 2013;92(2): 2171-80.

29. Gao J, Kong D, Wang Y, et al. Production of mesoporous activated carbon from tea fruit peel residues and its evaluation of methylene blue removal from aqueous solutions. Bioresources 2013;8(2): 214560 .

30. Kakavandi B, Jonidi A, Rezaei R, et al. Synthesis and properties of Fe $3 \mathrm{O}$ 4-activated carbon magnetic nanoparticles for removal of aniline from aqueous solution: equilibrium, kinetic and thermodynamic studies. J Environ Health Sci Eng 2013;10(1): 19.

31. Alahabadi A, Rezai Z, Rahmani-Sani A, et al. Efficacy evaluation of $\mathrm{NH} 4 \mathrm{Cl}$-induced activated carbon in removal of aniline from aqueous solutions and comparing its performance with commercial activated carbon. Desalination Water Treat 2016: 1-11.

32. Hu R, Dai S, Shao D, et al. Efficient removal of phenol and aniline from aqueous solutions using graphene oxide/polypyrrole composites. J Mol Liq 2015;203: 80-9.

33. Fakhri A. Adsorption characteristics of graphene oxide as a solid adsorbent for aniline removal from aqueous solutions: Kinetics, thermodynamics and mechanism studies. J Saudi Chem Soc 2013:21:S52S57.

34. Zhu H-Y, Fu Y-Q, Jiang R, et al. Adsorption removal of congo red onto magnetic cellulose/Fe $3 \mathrm{O}$ 4/activated carbon composite: equilibrium, kinetic and thermodynamic studies. Chem Eng J 2011;173(2): 494502.

35. Yanping $\mathrm{C}$, Cuiling R, Jichun Q, Xingguo C. Preparation and characterization of $\mathrm{Fe} 3 \mathrm{O}$ 4/graphene nanocomposite and investigation of its adsorption performance for aniline and p-chloroaniline. Appl Surf Sci 2012;261: 504-9.

36. Tarlani Azar M, Leili M, Taherkhani F, Bhatnagar A. A comparative study for the removal of aniline from aqueous solutions using modified bentonite and activated carbon. Desalination Water Treat 2016;57(51): 24430-43.

37. Kermani M, Pourmoghaddas H, Bina B, Khazaei Z. Removal of phenol from aqueous solutions by rice husk ash and activated carbon. Pak J Biol Sci 2006;9(10): 1905-10.

38. Yan H, Yang X, Chen J, et al. Synergistic removal of aniline by carbon nanotubes and the enzymes of Delftia sp. XYJ6. J Environ Sci 2011;23(7): 1165-70.

39. Xie X, Gao L, Sun J. Thermodynamic study on aniline adsorption on chemical modified multiwalled carbon nanotubes. Colloids Surf A Physicochem Eng Asp 2007;308(1): 54-9.

40. Cechinel MAP, de Souza AAU. Study of lead (II) adsorption onto activated carbon originating from cow bone. J Cleaner Prod 2014;65: 342-9. 